\title{
Analysis, Design, Modeling, and Control of an Interleaved-Boost Full-Bridge Three-Port Converter for Hybrid Renewable Energy Systems
}

Mira Albert, Maria del Carmen; Zhang, Zhe; Knott, Arnold; Andersen, Michael A. E.

Published in:

I E E E Transactions on Power Electronics

Link to article, DOI:

10.1109/TPEL.2016.2549015

Publication date:

2017

Document Version

Peer reviewed version

Link back to DTU Orbit

Citation (APA):

Mira Albert, M. D. C., Zhang, Z., Knott, A., \& Andersen, M. A. E. (2017). Analysis, Design, Modeling, and Control of an Interleaved-Boost Full-Bridge Three-Port Converter for Hybrid Renewable Energy Systems. IE E E Transactions on Power Electronics, 32(2), 1138 - 1155. https://doi.org/10.1109/TPEL.2016.2549015

\section{General rights}

Copyright and moral rights for the publications made accessible in the public portal are retained by the authors and/or other copyright owners and it is a condition of accessing publications that users recognise and abide by the legal requirements associated with these rights.

- Users may download and print one copy of any publication from the public portal for the purpose of private study or research.

- You may not further distribute the material or use it for any profit-making activity or commercial gain

- You may freely distribute the URL identifying the publication in the public portal 


\section{Analysis, Design, Modelling and Control of an Interleaved-Boost Full-Bridge Three-Port Converter for Hybrid Renewable Energy Systems}

Mira Albert, Maria del Carmen; Zhang, Zhe; Knott, Arnold; Andersen, Michael A. E.

Published in:

IEEE Transactions on Power Electronics

Publication date:

2016

Document Version

Peer reviewed version

Link to publication

\section{Citation (APA):}

Mira Albert, M. D. C., Zhang, Z., Knott, A., \& Andersen, M. A. E. (2016). Analysis, Design, Modelling and Control of an Interleaved-Boost Full-Bridge Three-Port Converter for Hybrid Renewable Energy Systems. IEEE Transactions on Power Electronics.

- You may freely distribute the URL identifying the publication in the public portal ? 


\title{
Analysis, Design, Modelling and Control of an Interleaved-Boost Full-Bridge Three-Port Converter for Hybrid Renewable Energy Systems
}

\author{
Maria C. Mira, Member, IEEE, Zhe Zhang, Member, IEEE, Arnold Knott, Member, IEEE, Michael A. \\ E. Andersen, Member, IEEE
}

\begin{abstract}
This paper presents the design, modelling and control of a three-port (TPC) isolated dc-dc converter based on interleaved-boost-full-bridge with pulse-width-modulation and phase-shift control for hybrid renewable energy systems. In the proposed topology, the switches are driven by phase-shifted PWM signals, where both phase angle and duty cycle are controlled variables. The power flow between the two inputs is controlled through the duty cycle, whereas the output voltage can be regulated effectively through the phase-shift. The primary side MOSFETs can achieve zero-voltage switching (ZVS) operation without additional circuitry. Additionally, due to the ac output inductor, the secondary side diodes can operate under zerocurrent switching (ZCS) conditions. In this work, the operation principles of the converter are analyzed and the critical design considerations are discussed. The dynamic behavior of the proposed ac inductor based TPC is investigated by performing state-space modelling. Moreover, the derived mathematical models are validated by simulation and measurements. In order to verify the validity of the theoretical analysis, design and power decoupling control scheme, a prototype is constructed and tested under the various modes, depending on the availability of the renewable energy source and the load consumption. The experimental results show that the two decoupled control variables achieve effective regulation of the power flow among the three ports.
\end{abstract}

Index Terms-Three-port converter, state-space modelling, renewable energy, energy storage, phase-shift and duty cycle control.

\section{INTRODUCTION}

$\mathrm{T}$ HE application of clean and renewable energy, such as solar, wind and hydrogen, has been a focus in academia

Manuscript received November 26, 2015; revised January 4, 2016; accepted March 15, 2016. Date of publication MONTH DAY,2016; date of current version MONTH DAY,2016

Recommended for publication by Associate Editor ADD

The authors are with the Department of Electrical Engineering, Technical University of Denmark, 2800 Kongens Lyngby, Denmark, (e-mail: mmial@elektro.dtu.dk; zz@elektro.dtu.dk; akn@elektro.dtu.dk; ma@elektro.dtu.dk).

Color versions of one or more of the figures in this paper are available online at http://ieeexplore.ieee.org.

Digital Object Identifier ADD and industry over the last decade [1], [2], [3]. Due to the intermittent feature of renewable energy sources, energy storage units are needed in order to balance the electricity generation and consumption within a power system having a high renewable energy penetration. Moreover, multiple energy sources hybridization can distinctly improve various aspects of system performance, such as decreasing cost, isolating energy sources from load fluctuations and enhancing the system dynamics. Hence, hybrid energy conversion systems are well suited for applications in which the average power demand is low whereas the load dynamics are relatively high [4], [5]. As a result, merging the renewable energy source elements together as a hybrid power conversion system, as well as controlling the power flows effectively has become a topic of interest.

In order to fulfil different system requirements, various hybrid system configurations and converter topologies have been proposed and investigated as reviewed in [3]. In applications where galvanic isolation is required, there are basically two categories classified as: multiple-converter conversion and multiple-port conversion. In the multipleconverter configurations, power converters are connected in parallel or in series in order to couple the energy sources and loads. By contrast, multiple-port power conversion systems can have high power density and low cost, due to the fact that some components and circuits in various power ports, such as transformers, rectifiers and output filters, can be shared as a common part along the power conversion path. Therefore, multiple-port converters have been receiving increased attention in recent years [6], [7], [8]. A general solution to obtain an isolated multiple-port converter is to adopt the magnetic coupling method, where various input power sources can be coupled with transformer windings or independent transformers [9], [10], [11]. In this solution, the multiport converter can be constructed from the basic high frequency switching cells, including the half-bridge (HB), full-bridge (FB), boost-half-bridge (BHB) and their combinations, according to the system constraints imposed by the features of the input power sources. Based upon this principle, a number of three-port (TPC) bidirectional dc-dc converters, which can 
fully isolate the various power ports and control the power flows into/out of each port, were reported in [12], [13], [14], [15], [16]. However, a large number of power switches have to be employed in those converters, resulting in increased cost and size. Besides the fully isolated multi-port topologies, partially isolated multiple-input converters, i.e. only some of the input/output ports are fully isolated, have been attracting more attention due to simple structure, less components and easy control. A dual-input dc-dc converter with BHB and FB switching cells was proposed in [17]. Two independent transformers are adopted in order to integrate both voltage-fed and current-fed power sources effectively. By combining a BHB with an LLC resonant tank, a wide-gain unidirectional two-port resonant converter is presented in [18], which can be extended to a TPC by replacing the low voltage dc bus with a voltage source. However, the control scheme to decouple the power flow will be complex due to the characteristics of the LLC circuitry. A systematic method for deriving a TPC with a diode rectifier was studied in [19], where the magnetizing inductance of an isolation transformer is utilized as a power interfacing element between the two non-isolated sources; however, this solution limits the converter's output power capability. A TPC based on an improved flyback-forward topology, with duty cycle and phase-shift control, proposed in [20], makes use of the leakage inductance of two coupled inductors to transfer power to the output port. However, in this solution the power delivering capability from the battery port to the output load is limited due to the flyback operation. Two three-port converter (TPC) topologies were proposed in [21] and [22] by integrating a boost converter into a phase-shift full-bridge buck converter, hence, the two non-isolated input ports, which connect with the renewable energy sources, are isolated from the load. After that, the topologies and their derived structures are investigated and presented in [23], [24], [25], [26]. By adopting the phase-shift with duty cycle control, the decoupled power flow can be controlled effectively among the various ports in a certain operating range. However, due to the employed output dc inductor, all the output rectifier diodes operate under hard switching condition, and suffer from high voltage stress and reverse recovery losses. Moreover, like other phase-shift zero-voltage switching (ZVS) converters, the duty cycle loss issue due to the leakage inductance still occurs. A FB TPC with duty cycle and phase-shift control derived from an interleaved boost-full-bridge (BFB) and a bridgeless boost rectifier is presented in [27]. This topology reduces the input current ripple and current stress of the input ports because of the $180^{\circ}$ phase-shift operation of the primary switching legs. The output port regulation is achieved through the phase-shift between the primary and secondary switches. Therefore, two extra active switches in the secondary side are necessary to control the output port power flow, both with high side driver requirements, which increases the circuit complexity. Moreover, the body diode of the secondary MOSFETs operate under hard switched current conditions generating reverse recovery losses.

The goal of this work is to propose, analyse and design a TPC topology for hybrid renewable energy systems. The proposed topology, as illustrated in Fig. 1, is derived from a ZVS HB inductive dc-dc converter with an active clamped circuit [28], [29]. By replacing the clamp capacitor in the ZVS circuit with the second voltage source, an additional input port can be obtained. Compared to the topologies in [21] and [25], the rectifier diodes achieve zero-current switching (ZCS) at turn-off avoiding reverse recovery losses. Additionally, the voltage across the diodes is inherently clamped by the output capacitor $C_{\mathrm{O}}$, therefore, voltage rings caused by the stray inductance can be eliminated. Furthermore, the secondary freewheeling current is limited due to the absence of a dc output inductor. Moreover, this converter is superior to its LLC counterparts due to lower complexity of the modulation and control. Compared to previous research on TPC topologies, modelling and analysis of dynamic performance with multiple control parameters are seldom reported. The major contribution of this paper is to analyse the relation between the two control variables, phase-shift and duty cycle, and the system dynamics based on the converter small-signal model. The derived mathematical model is verified by simulations as well as experimental measurements. Based on the small-signal model, the power flow control is designed and the converter is tested under various operation modes, i.e. dual input (DI) mode, dual output (DO) mode and single input single output (SISO) mode.

This paper is organized into seven sections: following the introduction in Section I, the topology and operation principle of the proposed converter are presented in Section II. Design considerations and the associated guidelines are given in Section III. The dynamic behaviour is investigated in Section IV. The power flow regulation scheme is analysed in Section. $\mathrm{V}$. The corresponding experimental results from a laboratory prototype are provided and discussed in Section VI. As a final point, the conclusion is presented in Section VII.

\section{Circuit Description AND OPERATION PRINCIPLES}

The studied topology in Fig. 1 consists of two input inductors, $L_{1}$ and $L_{2}$, an ac inductor $L_{a c}$, four power MOSFETs $M_{1} \sim M_{4}$, and a high frequency transformer with a turn ratio of $1: n$. The ac inductor, which is the sum of the leakage inductance and the auxiliary inductance, is the power interface element between primary and secondary sides of the transformer. Switches $M_{1}, M_{2}$ and $M_{3}, M_{4}$ are driven with complementary gate signals with a deadband. $V_{1}$ and $V_{2}$ represent the input voltages; $i_{L 1}$ and $i_{L 2}$ are defined as the input inductor currents;

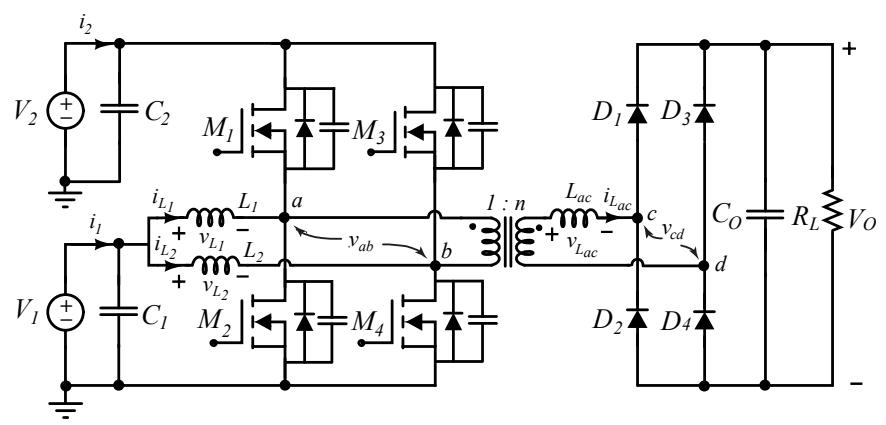

Fig. 1. Topology of the proposed TPC for hybrid renewable energy systems. 
$v_{a b}$ is the voltage between the midpoints of the bidirectional interleaved boost switching legs, and $i_{L a c}$ is the current of the secondary side winding. In order to decouple the two inputs, $V_{1}$ and $V_{2}$, and regulate the output voltage accurately, both the duty cycle and the phase-shift angle are adopted as the control variables simultaneously. The duty cycle of the power switches is used to adjust the power among the two independent sources, and the phase-shift angle between the midpoints of the full bridge is employed to regulate the power flow to the output port.

Through the phase-shift with duty cycle control, and according to the availability of the renewable energy source and the load demand, the proposed converter can operate in various operating modes: in DI mode when the load demand is higher than the available power from the renewable energy source and the energy storage element delivers the extra energy to the load; in DO mode when the input power is higher than the load power demand and the energy storage element balances the power by storing the excess energy; and in SISO mode when power transfers between the two inputs or from one of the inputs to the output port.

For the theoretical analysis it is assumed that inductors $L_{1}$, $L_{2}$ and capacitors $C_{1}, C_{2}$, and $C_{\mathrm{O}}$ are big enough and the deadband effect is negligible. Due to the operation symmetry, the variation range of the phase-shift angle $\varphi$ is: $0<\varphi<\pi$. Depending on the duty cycle and its relationship with the phase-shift angle, there are three operational cases existing, based on the current shape of the ac inductor, which can be classified as completely demagnetized, partially magnetized and fully magnetized.

Fig. 2 and Fig. 3 shows the equivalent circuits during the defined time intervals and the key operating waveforms when the ac inductor current is completely demagnetized in each period. During the first subinterval, i.e. $\left[0 \sim t_{1}\right]$ as shown in Fig. $2(a), \quad M_{2}$ and $M_{3}$ are conducing simultaneously, so that $L_{1}$ and $L_{2}$ are charged and discharged, respectively. The voltage across midpoints $a$ and $b$ is clamped at $-V_{2}$, therefore, $L_{a c}$ is charged with $\left(n V_{a b}-V_{c d}\right)$. The ac inductor current is negative, as denoted in Fig. $2(a)$, and satisfies

$$
I_{L a c p k}=\frac{-n V_{2}+V_{O}}{L_{a c}} \cdot \Phi T
$$

where the phase-shift angle normalized to the period is defined as

$$
\Phi=\frac{\varphi}{2 \pi}
$$

During the interval $\left[t_{1} \sim t_{2}\right]$ in Fig $2(b), M_{4}$ is triggered at $t_{1}$ and $L_{1}$ and $L_{2}$ are charged. Since in this interval the voltage across the transformer, $v_{a b}$ is clamped at zero, $L_{a c}$ is discharged with a slope determined by the output voltage $V_{O}$. Defining $\beta$ as the interval $\left[t_{1} \sim t_{2}\right]$ normalized to the period as in (3), the ac inductor discharge interval $\Delta t$ can be calculated as shown in (4).

$$
\begin{aligned}
& \beta=\frac{n V_{2}-V_{O}}{V_{O}} \cdot \Phi \\
& \Delta t=t_{2}-t_{1}=\beta \cdot T
\end{aligned}
$$

When the ac inductor current reaches zero the bridge rectifier diodes stop conducting, which concludes the second subinterval.
During subinterval $\left[t_{2} \sim t_{3}\right], L_{1}$ and $L_{2}$ will continue being charged, as represented in Fig. 2 (c), until $M_{2}$ is turned-off at $t_{3}$. Since the ac inductor current is completely demagnetized during the previous interval, in this state there is no power transferring from the primary side to the output port.

The equivalent circuit during interval $\left[t_{3} \sim t_{4}\right]$ is presented in Fig. $2(d)$. It can be seen that the operation principle is symmetrical to that of $\left[0 \sim t_{1}\right]$, thus

$$
I_{\text {Lac }}\left(t_{4}\right)=-I_{\text {Lac }}\left(t_{1}\right)
$$

From the key waveforms shown in Fig. 3, it can be observed the phase-shift value, $\Phi$, should be smaller than the duty cycle $(D)$ and the complement of the duty cycle $(1-D)$, as expressed in (6).

$$
\Phi<\min [D,(1-D)]
$$

Using equations (1) to (4), the output voltage of the converter can be obtained as in (7).

$$
V_{O}=\frac{n V_{2}}{k} \cdot \Phi\left(-\Phi+\sqrt{\Phi^{2}+2 k}\right)
$$

where the parameter $k$ is a dimensionless magnitude defined by the inductance, the output load and switching frequency as shown in (8).

$$
k=\frac{2 L_{a c}}{R_{L} T}
$$

The relationship between $V_{1}$ and $V_{2}$ is obtained as

$$
V_{2}=\frac{V_{1}}{(1-D)}
$$

It is noteworthy that in this operation mode the energy transferred to the output port does not directly depend on the duty cycle. Therefore, in the completely demagnetized operating mode the power flow from $V_{1}$ and $V_{2}$ to the output port will be entirely controlled by $\Phi$.

If the inductor current $i_{L a c}$ does not decrease to zero before $M_{2}$ is triggered, the ac current is partially magnetized, as shown in Fig. $4(a)$. The boundary condition between completely demagnetized and partially magnetized inductor current can then be derived as

$$
\Delta t+\Phi T \leq(1-D) T
$$

Substitution of (4) into (10) leads to (11).

$$
\Phi \leq \frac{(1-D)}{M}
$$

where the relation between the input and output ports is defined as

$$
M=\frac{n V_{a b}}{V_{c d}}=\frac{n V_{1}}{(1-D) V_{O}}=\frac{n V_{2}}{V_{O}}
$$

In the same way, if the $i_{L a c}$ does not reach zero before $M_{2}$ is turned off, the ac current becomes fully magnetized, as shown in Fig. $4(b)$. As it can be observed from the inductor current shape in the key waveforms shown in Fig. 4, these operation modes, i.e. partial and fully magnetized, allow to transfer higher power to the output than the completely demagnetized counterpart. However, during the time intervals in which the inductor current does not reach zero, $\left[0 \sim t_{1}\right]$ in the partially magnetized mode and $\left[0 \sim t_{1}\right]$ and $\left[t_{3} \sim t_{4}\right]$ in the fully 


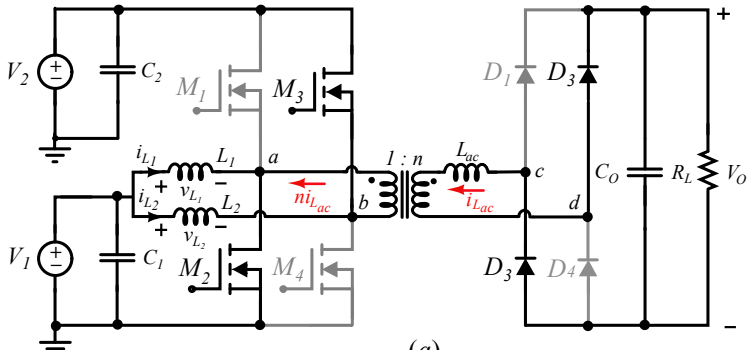

(a)

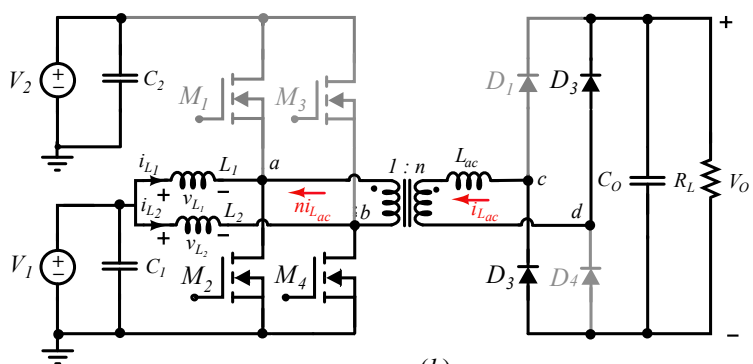

(b)

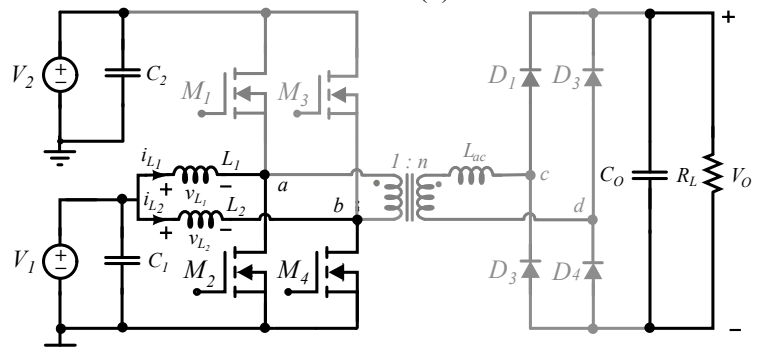

(c)

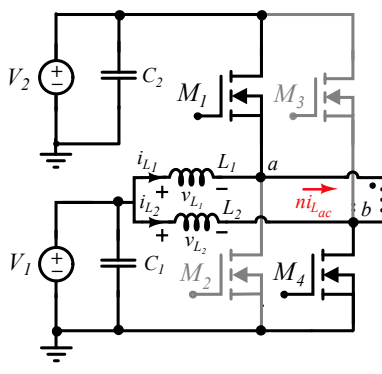

(d)
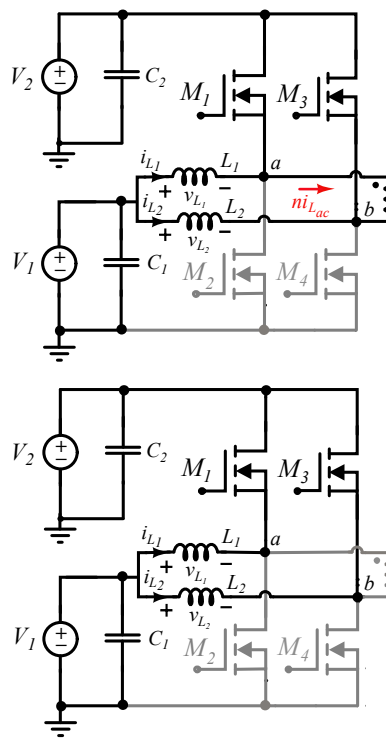

(e)
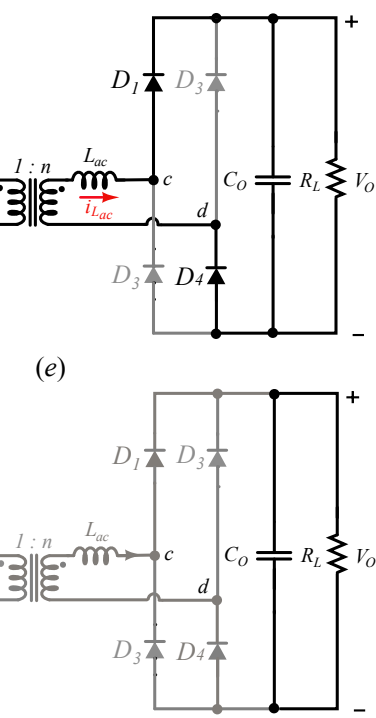

$(f)$

Fig. 2. Equivalent operating circuits for completely demagnetized output inductor current (left): (a) time interval [0 $\left.t_{1}\right]$, (b) time interval $\left[t_{1} \sim t_{2}\right],(c)$ time interval $\left[t_{2} \sim t_{3}\right],(d)$ time interval $\left[t_{3} \sim t_{4}\right],(e)$ time interval $\left[t_{4} \sim t_{5}\right]$ and $(f)$ time interval $\left[t_{5} \sim t_{6}\right]$.

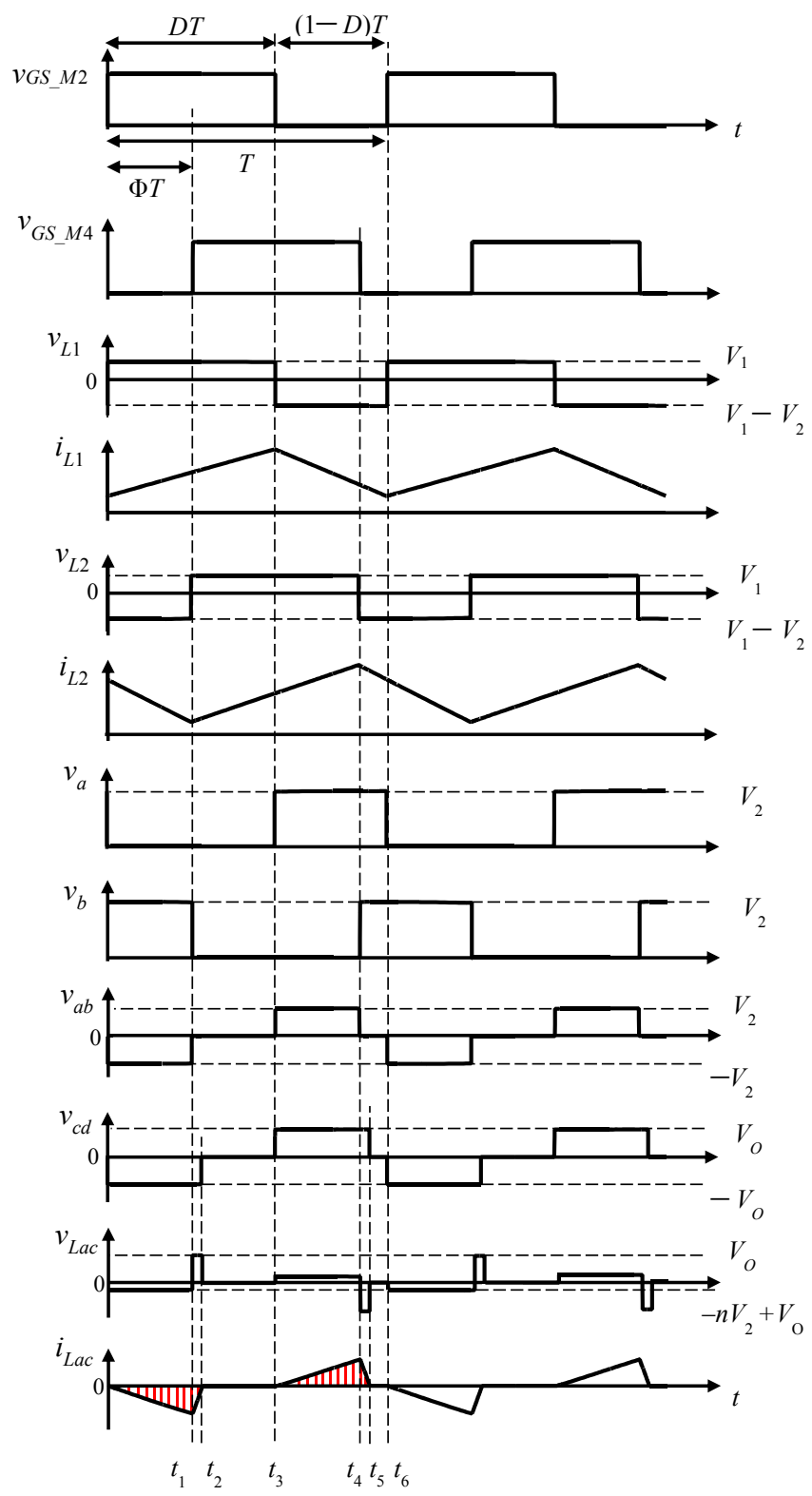

Fig. 3. Completely demagnetized ac inductor current key operating waveforms.

magnetized mode, the same current flowing through the ac inductor is flowing in the primary side and therefore, sent back to the source $V_{2}$. Therefore, when the input voltage and the inductor current are not in phase reactive power is generated, which results in higher current stress in the converter primary side and, therefore, higher losses than in the completely demagnetized operating mode.

In the same way than the completely demagnetized operation mode, the partially and fully magnetized operation modes can be analysed by describing the converter operation intervals. By solving the equation relating the average of the rectified inductor current (13) and the load current $\left(V_{O} / R_{L}\right)$, the output voltage of the converter operating in partially magnetized operation mode can be obtained.

$$
I_{\text {Lacrec }, a v g}=\frac{V_{O} \Phi\left(\Phi(1-D)\left(M^{2}-2 M-1\right)-\Phi^{2}-(1-D)^{2}\right)}{L_{a c} f(M+1)^{2}}
$$




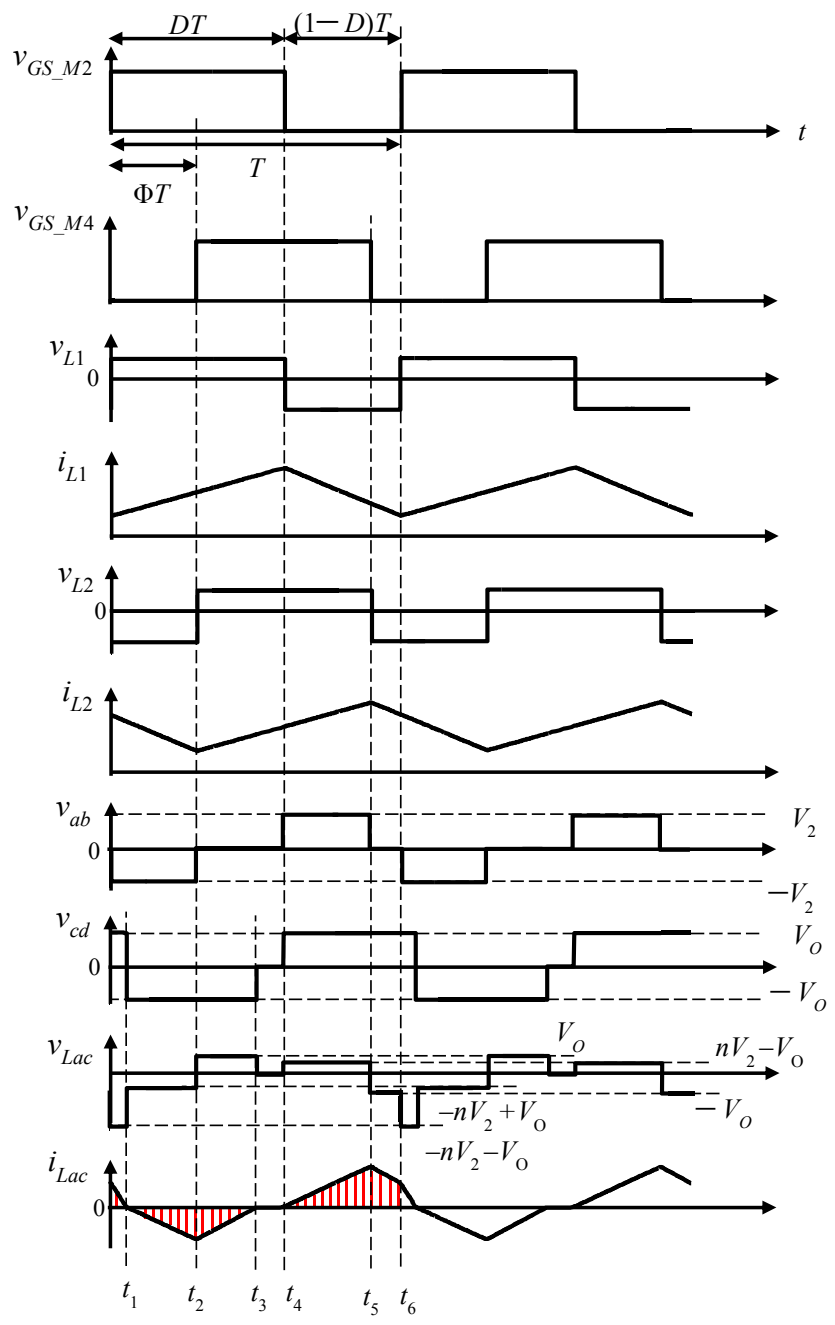

(a)

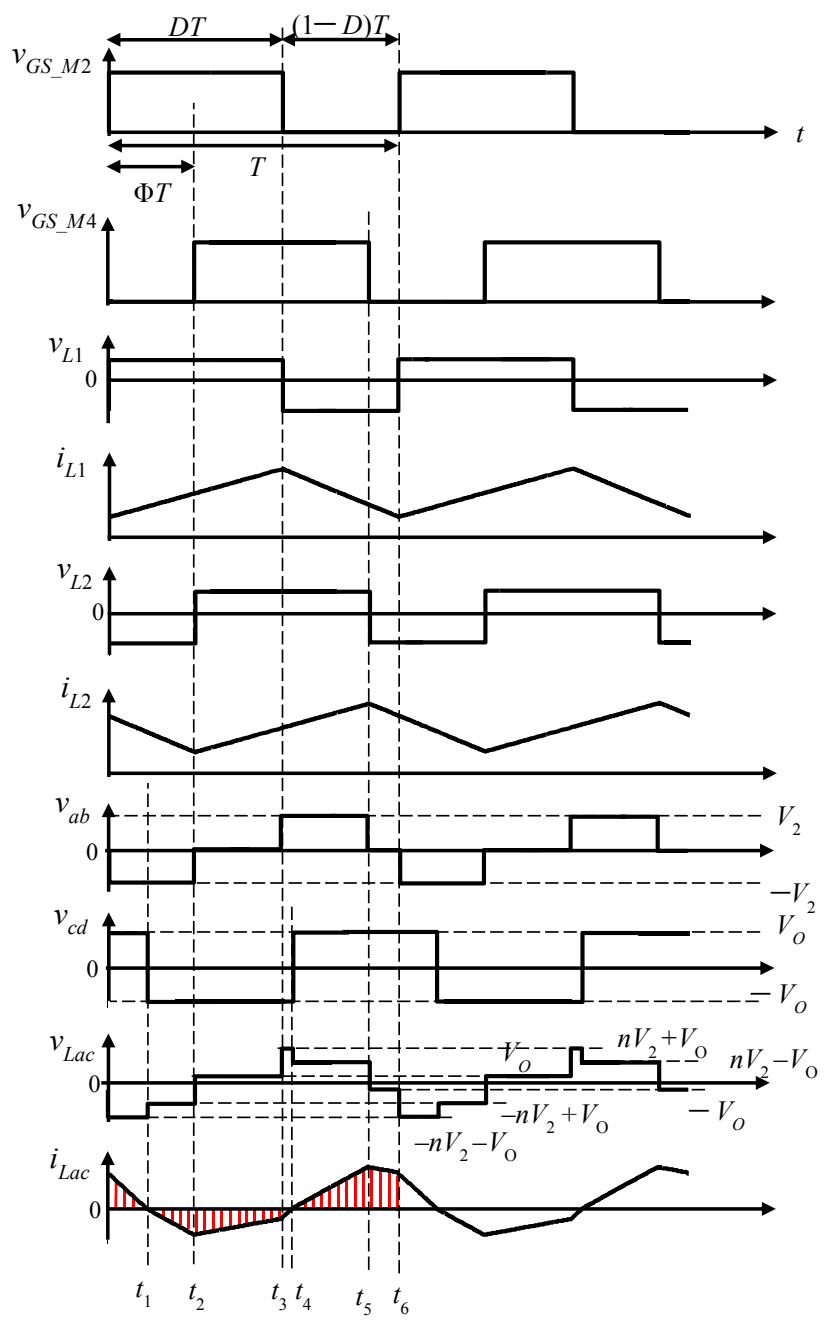

(b)

Fig. 4. (a) Partially magnetized ac inductor current key operating waveforms. (b) Fully magnetized ac inductor current key operating waveforms.

The time intervals corresponding to the fully magnetized operating mode can be calculated according to the waveforms shown in Fig. $4(b)$, by solving the system of equations formed by the ac inductor volt-second balance and the rectified ac inductor current. By defining the interval $\left[0 \sim t_{1}\right]$ normalized to the period as shown in (14), the time intervals as a function of the phase-shift and the duty cycle parameters can be written as

$$
\begin{gathered}
\alpha=\frac{1}{4} \cdot\left(2 D+2 \Phi+2 k-\sqrt{4 D(1-D)+4 \Phi(1-\Phi)+4 k^{2}-1}\right) \\
t_{1}=\alpha \cdot T \\
t_{2}-t_{1}=(\Phi-\alpha) \cdot T \\
t_{3}-t_{2}=(D-\Phi) \cdot T \\
t_{4}-t_{3}=\left(\alpha-D+\frac{1}{2}\right) \cdot T \\
t_{5}-t_{4}=\left(\Phi-\alpha+D-\frac{1}{2}\right) \cdot T \\
t_{6}-t_{5}=(1-D-\Phi) \cdot T
\end{gathered}
$$

The output voltage as a function of the phase-shift value and the duty cycle can be calculated by

$$
V_{O}=n V_{2}\left(-2 k+\sqrt{4 D(1-D)-4 \Phi(1-\Phi)+4 k^{2}-1}\right)
$$

Partially and fully magnetized operation allow for higher power transfer for the same inductor value than the completely demagnetized mode. This is due to the increased charge per switching cycle delivered to the output capacitor, which can be observed in the highlighted area of the ac inductor current shown in Fig. $4(a)$ and $(b)$ compared to the completely demagnetized inductor current shown in Fig. 3. However, as discussed before, these operating modes move the current stress from the converter secondary to the primary side due to the generated reactive power, which acts in detriment of the efficiency in step up applications. Moreover, as it can be seen by comparing (7) and (21), when the converter leaves the completely demagnetized mode, the converter output voltage is no longer controlled solely by the phase-shift angle. This characteristic increases the difficulty in the implementation of the dual power flow converter control strategy. Considering all the aforementioned characteristics, completely demagnetized ac inductor current is the preferred operation mode. 


\section{Design COnSIDERATIONS}

In this section, design guidelines about the soft-switching operation and the rms current distribution of the primary switches for the completely demagnetized operation mode are discussed.

\section{A. Soft-Switching Constraints}

The proposed converter, unlike the conventional phase-shift full-bridge ZVS converter, has a relatively more complicated ZVS performance to analyse due to the input inductor currents $i_{L 1}$ and $i_{L 2}$. ZVS can be deduced on the precondition that the anti-parallel diode of the MOSFET must conduct before the MOSFET is triggered. In other words, the main devices are turned-off with a positive current flowing and then the current diverts to the opposite diode, which allows the in-coming MOSFET to be switched-on under zero voltage condition. Therefore, the current flowing through MOSFETs $M_{1} \sim M_{4}$ must be negative when the corresponding MOSFET is triggered. Taking into account the amount of stored energy in the MOSFETs' output capacitance $\left(C_{O S S}\right)$, in order to obtain ZVS at turn-on the following relationships must be satisfied

$$
\left\{\begin{array}{ccc}
I_{L 1, \text { max }}-n i_{L a c}\left(t_{3}\right)>I_{\text {min }} & \text { for } & M_{1} \\
I_{L 1, \text { min }}-n i_{L a c}\left(t_{0}\right)<I_{\text {min }} & \text { for } & M_{2} \\
I_{L 2, \max }+n i_{L a c}\left(t_{4}\right)>I_{\text {min }} & \text { for } & M_{3} \\
I_{L 2, \min }+n i_{L a c}\left(t_{1}\right)<I_{\text {min }} & \text { for } & M_{4}
\end{array}\right.
$$

where

$$
\begin{gathered}
I_{L i, \max }=\frac{P_{1}}{2 V_{1}}+\frac{V_{1}(1-D) T}{2 L_{i}} \quad(i=1,2) \\
I_{L i, \min }=\frac{P_{1}}{2 V_{1}}-\frac{V_{1}(1-D) T}{2 L_{i}} \quad(i=1,2) \\
I_{\text {min }}=\sqrt{\frac{\left(2 \cdot C_{\text {OSS }}\right) \cdot V_{2}^{2}}{L_{a c}}}
\end{gathered}
$$

As the waveforms shown in Fig. 4, where $\Phi<(1-D)$ and $D>0.5$, when the input $V_{1}$ provides power to the load, $M_{2}$ in the leading half-bridge cannot operate under ZVS. However, $M_{4}$ in the lagging half-bridge can achieve ZVS if the constraints depicted in Fig. 5 are satisfied. As it can be observed in Fig. 5, as the power flow to the output port increases, the turn-on condition of $M_{4}$ moves towards the ZVS region due to the increased negative ac inductor peak current. However, increasing the power flow from the input port $V_{1}$ to the bidirectional port $V_{2}$ has the opposite effect due to an increased $I_{L 2, \min }$ value. It is important to observe the influence of the input inductor and ac inductor values on the switch ZVS region. Increasing both of the inductor values reduces the ZVS region, since $I_{L 2, \min }$ increases due to a reduced input inductor ripple current, and $n i_{\text {Lac }}\left(t_{1}\right)$ decreases for larger ac inductor values. Regarding the high side switches $M_{1}$ and $M_{3}$, since they operate as synchronous rectifiers in the interleaved boost stage, both can operate under ZVS inherently, because the reflected ac inductor current, $n i_{L a c}\left(t_{3}\right)$, is equal to zero and $n i_{\text {Lac }}\left(t_{4}\right)$ is always positive.

A significant advantage of the proposed TPC topology is that the diodes on the secondary side can operate under ZCS conditions. As it can be observed in Fig. 3 and Fig. 4, the

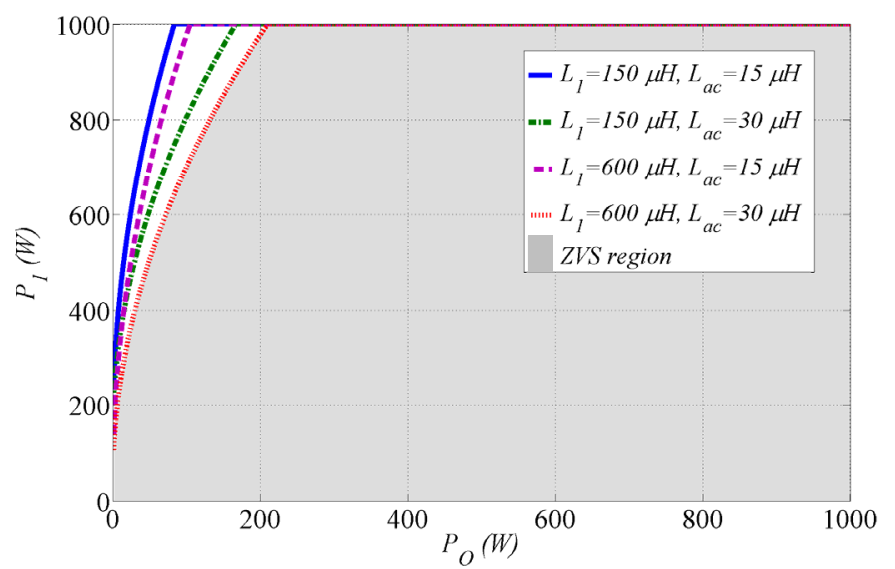

Fig. 5. ZVS range (operating conditions $V_{1}=50 \mathrm{~V}, V_{2}=100 \mathrm{~V}$ and $V_{\mathrm{O}}=380$ V).

output bridge rectifier always changes its conduction state (edges of the waveform $v_{c d}$ ) when the ac inductor current reaches zero for all operating conditions. Therefore, due to the use of an ac inductor, the diodes on the secondary side always turn-off under ZCS conditions, which avoids the reverse recovery losses and makes it possible to use conventional silicon (Si) diodes.

\section{B. Selection of MOSFETs and Diodes}

Like all half-bridge boost derived converters, the current distribution in the primary side MOSFETs is unequal. In the proposed converter the analysis on the rms current distribution is more complex due to the variable phase-shift angle. If $\varphi=\pi$, the rms current of the MOSFETs can be calculated by,

$$
\begin{aligned}
& I_{M_{1}, r m s}=I_{M_{3}, r m s}=\sqrt{n I_{L_{a c}, r m s}{ }^{2}-I_{L_{1}, r m s}{ }^{2}} \\
& I_{M_{2}, r m s}=I_{M_{4}, r m s}=\sqrt{n I_{L_{a c}, r m s}{ }^{2}+I_{L_{1}, r m s}{ }^{2}}
\end{aligned}
$$

According to the operating waveform of $i_{L a c}$ shown in Fig. 3 and (1) - (4), the rms value of the ac inductor current can be obtained as

$$
I_{L a c, r m s}=I_{L a c p k} \sqrt{\frac{2}{3}(\Phi+\beta)}
$$

where $I_{\text {Lac } p k}=I_{\text {Lac }}\left(t_{4}\right)=\left|I_{L a c}\left(t_{1}\right)\right|$ is given in (1).

Fig. 6 shows the switches' rms current as a function of duty cycle $D$. It can be found that for $\varphi=\pi, M_{2}$ and $M_{4}$ have the maximum rms current (worst case for $M_{2}$ and $M_{4}$ ), whereas $M_{1}$ and $M_{3}$ have the minimum rms current. Also, it can be observed that when $\varphi \neq \pi$, the current distribution will be more equal than the case $\varphi=\pi$. This phenomenon must be considered when choosing components and deciding thermal design for the proposed converter.

The current flowing through the diodes on the secondary side is distributed equally, and the average current in each diode can be calculated as

$$
I_{D_{1}, D_{4}, \text { avg }}=I_{D_{2}, D_{3}, \text { avg }}=\frac{1}{2} \cdot I_{L a c p k} \cdot(\Phi+\beta)
$$

According to the operation principle analysis, the voltage stress over the MOSFETs is the maximum voltage of $V_{2}$. The voltage stress across the diodes is the maximum output voltage owing to the voltage clamp effect by the output capacitor. 


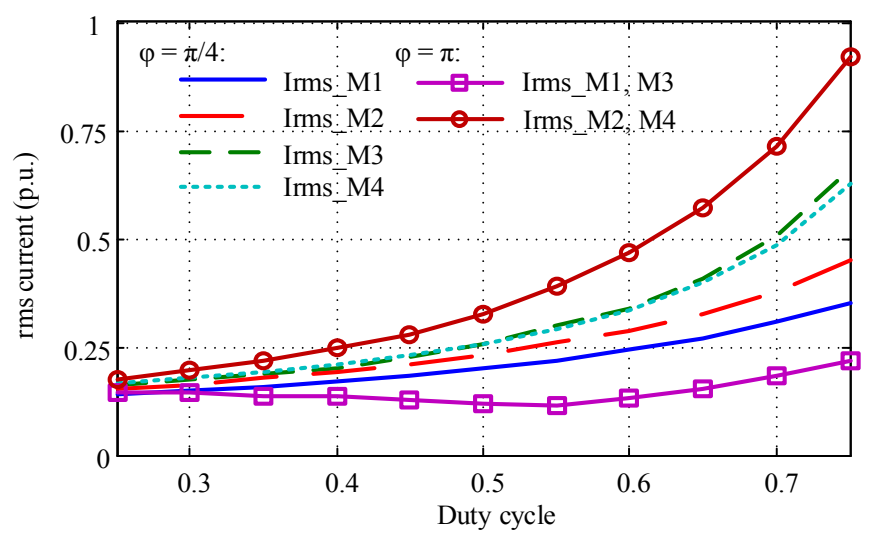

Fig. 6. Switches' rms current as a function of duty cycle $D$.

\section{State-Space Modelling}

In this section, state-space average modelling of the proposed TPC is presented. This technique to modelling switching dc-dc converters [30], which results in a dynamic linear model in terms of state-space equations, is used in this work. Due to the inherent sampling process of switched-mode converters, averaged models can accurately predict the behaviour up to half of the switching frequency [31]. If precise modelling beyond the switching frequency is required, i.e. in self-oscillating control schemes, a discrete-time approach for modelling switched-mode controllers can be used [32].

From the key operating waveforms illustrated in Fig. 3, it can be observed that the ac inductor charge and discharge always depends on the converter input voltage $V_{2}$, the converter output voltage $V_{O}$ and the phase-shift angle, whereas voltages $V_{1}$ and $V_{2}$ are regulated by the duty cycle. Therefore, the proposed topology can be dynamically modelled as two individual converters: a bidirectional interleaved boost converter, which balances the power flow within the two input sources, and a phase-shift full-bridge converter or single active bridge converter, which delivers the power to the load through the ac inductor. As a result, the proposed converter offers independent controllability by using duty cycle and phase-shift as control variables, and reutilizes the primary side switches to regulate the two power flows. The high integration of the two structures in a TPC results in a topology with lower component number and higher power density than multipleconverter systems. Moreover, as previously discussed, in the completely demagnetized case the energy transferred to the output port does not depend on the converter duty cycle; therefore, the two control variables, phase-shift $\Phi$ and dutycycle $D$, are completely decoupled. Fig. 7 shows the integration of the bidirectional interleaved boost converter (BIBC) and the phase-shift full-bridge (PSFB) converter as a TPC topology.

As previously discussed, the completely demagnetized operation is the preferred operation mode, however, the converter can enter any of the other operating modes depending on the two input port voltages, the duty-cycle requirement and the output port loading conditions. Therefore, in order to ensure stability of the converter under all possible operating conditions, the dynamic modelling in the fully magnetized mode is also investigated.

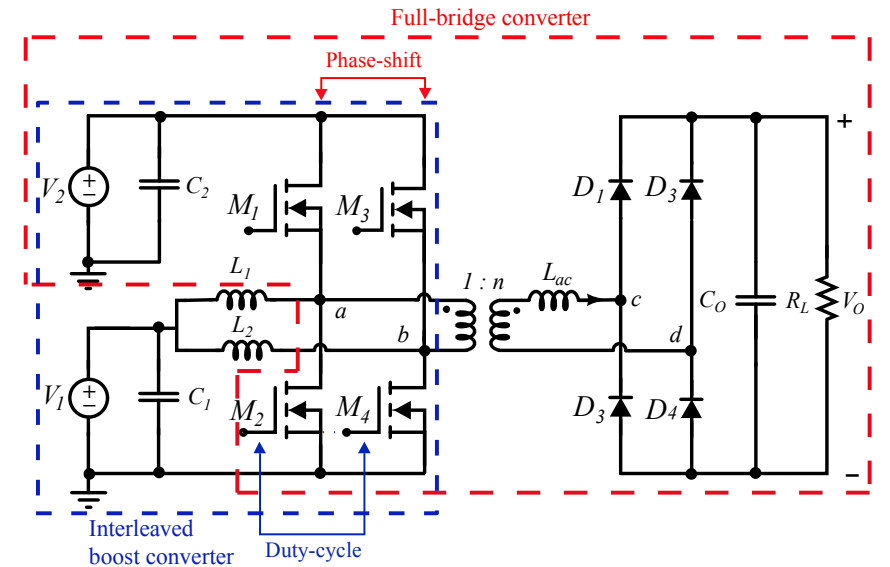

Fig. 7. Integration of the interleaved boost converter and phase-shift fullbridge converter as a TPC.

\section{A. State-Space Modelling of the Phase-Shift Full-Bridge (PSFB) Converter}

State-space average modelling of the phase-shift full-bridge (PSFB) converter is performed in this section. First, the completely demagnetized operating mode is analysed. The rectified ac inductor current and the output capacitor voltage are selected as state-variables, i.e. $x=\left[\begin{array}{ll}i_{L_{a c}} & v_{C_{O}}\end{array}\right]^{T}$. Fig. 8 shows the voltage and current across the ac inductor during the different switching states, together with the rectified ac inductor current. The state and input matrices are averaged over a period by multiplying them by the corresponding time interval. As shown in Fig. 3, there are six conduction states; however, since the state-variable is the rectified ac inductor current, the charge and discharge of the ac inductor during time intervals $\left[0 \sim t_{1}\right]$ and $\left[t_{1} \sim t_{2}\right]$ is equivalent to time intervals $\left[t_{3} \sim t_{4}\right]$ and $\left[t_{4} \sim t_{5}\right]$, as shown in Fig. 8. Notice that because two control variables are used, duty cycle and phaseshift, time intervals $\left[t_{2} \sim t_{3}\right]$ and $\left[t_{5} \sim t_{6}\right]$ are not the same since they are related to $D$ and $(1-D)$, respectively.

The system is perturbed around a quiescent operating point $\left(X+\hat{x}, \Phi+\hat{\Phi}, \beta+\hat{\beta}, V_{2}+\hat{v}_{2}\right) \quad$ where $X \gg \hat{x}, \quad$ and linearized by neglecting the second order terms. Separating the $\mathrm{dc}$ and ac part of the linearized model, the steady-state operating point (30) and the small-signal model (31) are obtained.

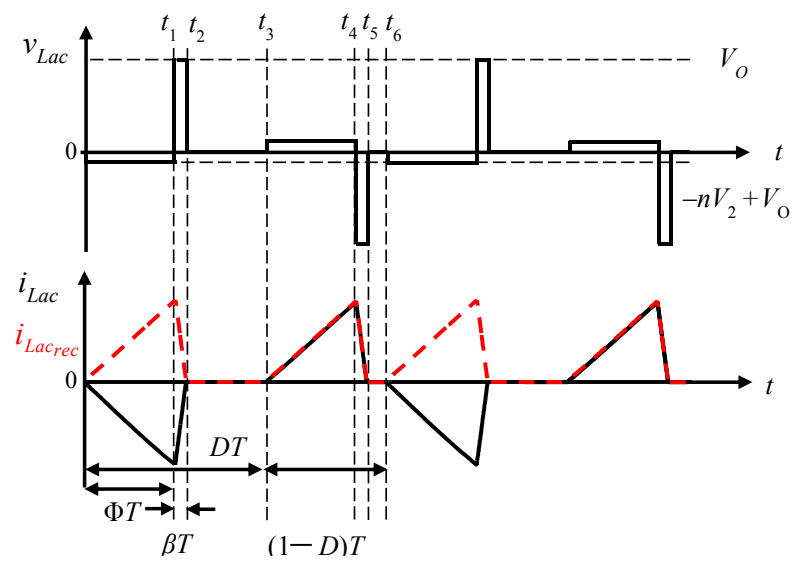

Fig. 8. Voltage and current across the ac inductor $L_{a c}$ (continuous) and rectified ac inductor current (dashed) in completely demagnetized operation mode. 


$$
\begin{aligned}
& X=\left[\begin{array}{c}
I_{L a c} \\
V_{C_{O}}
\end{array}\right]=-A^{-1} B V_{2}=\left[\begin{array}{c}
\frac{n V_{2} \Phi}{2 R_{L}(\Phi+\beta)^{2}} \\
\frac{n V_{2} \Phi}{\Phi+\beta}
\end{array}\right] \\
& \dot{\hat{x}}=A \hat{x}+B \hat{v}_{2}+\left[\left(2 A_{4}-2 A_{6}\right) X+\left(2 B_{4}-2 B_{6}\right) V_{2}\right] \hat{\Phi}+ \\
& +\left[\left(2 A_{5}-2 A_{6}\right) X+\left(2 B_{5}-2 B_{6}\right) V_{2}\right] \hat{\beta} \\
& \dot{\hat{x}}=\left[\begin{array}{cc}
0 & -\frac{2(\Phi+\beta)}{L_{a c}} \\
\frac{2(\Phi+\beta)}{C_{O}} & -\frac{1}{C_{O} R_{L}}
\end{array}\right] \hat{x}+\left[\begin{array}{c}
\frac{2 n \Phi}{L_{a c}} \\
0
\end{array}\right] \hat{v}_{2}+ \\
& +\left[\begin{array}{c}
\frac{2 n V_{2} \alpha}{L_{a c}(\Phi+\beta)} \\
\frac{n V_{2} \Phi}{C_{O} R_{L}(\Phi+\beta)^{2}}
\end{array}\right] \hat{\Phi}+\left[\begin{array}{c}
-\frac{2 n V_{2} \Phi}{L_{a c}(\Phi+\beta)} \\
\frac{n V_{2} \Phi}{C_{O} R_{L}(\Phi+\beta)^{2}}
\end{array}\right] \hat{\beta}
\end{aligned}
$$

where the averaged state and input matrices are given by

$$
\begin{array}{r}
A=2 A_{4} \Phi+2 A_{5} \beta+A_{6}(1-(2 \Phi+2 \beta)) \\
B=2 B_{4} \Phi+2 B_{5} \beta+B_{6}(1-(2 \Phi+2 \beta)) \\
A_{4}=\left[\begin{array}{cc}
0 & -\frac{1}{L_{a c}} \\
\frac{1}{C_{O}} & -\frac{1}{R_{L} C_{O}}
\end{array}\right] \quad A_{5}=\left[\begin{array}{cc}
0 & -\frac{1}{L_{a c}} \\
\frac{1}{C_{O}} & -\frac{1}{R_{L} C_{O}}
\end{array}\right] \\
A_{6}=\left[\begin{array}{cc}
0 & 0 \\
0 & -\frac{1}{R_{L} C_{O}}
\end{array}\right] \\
B_{4}=\left[\begin{array}{c}
\frac{n}{L_{a c}} \\
0
\end{array}\right] \quad B_{5}=\left[\begin{array}{l}
0 \\
0
\end{array}\right] \quad B_{6}=\left[\begin{array}{l}
0 \\
0
\end{array}\right]
\end{array}
$$

The discharge parameter $\beta$ is defined in (3) and the phaseshift value $\Phi$ s given by

$$
\Phi=\frac{V_{O}}{\sqrt{2}} \sqrt{\frac{-k}{n V_{2}\left(V_{O}-n V_{2}\right)}}
$$

In order to obtain the dynamic model of the converter in the completely demagnetized mode, additional constrains need to be applied. The first constraint comes from the fact that the inductor current becomes zero for a portion of the switching period. Applying the constraint defined in (36) to the ac model presented in (31), leads to (37). As a result, the inductor dynamic equation turns into a static equation, as shown in (38), meaning that the ac inductor current does not behave as a true state-space variable since it losses its dynamic properties [33].

$$
\begin{gathered}
\frac{d \hat{i}_{L_{a c}}}{d t}=0 \\
\hat{\beta}=\frac{-(\Phi+\beta)}{V_{O}} \hat{v}_{O}+\frac{n \Phi}{V_{O}} \hat{v}_{2}+\frac{n V_{2} \beta}{V_{O}(\Phi+\beta)} \hat{\Phi}
\end{gathered}
$$

$$
\begin{gathered}
\dot{\hat{x}}=\left[\begin{array}{cc}
0 & 0 \\
\frac{2(\Phi+\beta)}{C_{O}} & -\frac{2}{C_{O} R_{L}}
\end{array}\right] \hat{x}+\left[\begin{array}{c}
0 \\
\frac{n \Phi}{C_{O} R_{L}(\Phi+\beta)}
\end{array}\right] \hat{v}_{2} \\
+\left[\begin{array}{c}
0 \\
\frac{n V_{2}}{C_{O} R_{L}(\Phi+\beta)}
\end{array}\right] \hat{\Phi}
\end{gathered}
$$

The second constraint is obtained from the average of the inductor current as shown in (39).

$$
i_{\text {Lac }}=f\left(v_{2}, v_{O}, \Phi, L_{a c}, T\right)=\frac{i_{L a c, p k}}{2} \frac{\left(n V_{2}-V_{O}\right) \Phi}{R_{L} k}
$$

The perturbation equation is found by taking the partial derivatives of (39) as shown in (40).

$$
\begin{gathered}
\hat{i}_{L a c}=\frac{\partial i_{L a c}}{\partial v_{O}} \hat{v}_{O}+\frac{\partial i_{L a c}}{\partial v_{2}} \hat{v}_{2}+\frac{\partial i_{L a c}}{\partial \Phi} \hat{\Phi} \\
\hat{i}_{L a c}=\frac{\Phi}{R_{L} k} \hat{v}_{O}+\frac{n \Phi}{R_{L} k} \hat{v}_{2}+\frac{\left(n V_{2}-V_{O}\right)}{R_{L} k} \hat{\Phi}
\end{gathered}
$$

By applying the perturbation equation (40) to (38), the phase-shift-to-output voltage transfer function in completely demagnetized mode is obtained (41). As previously discussed, in this operating mode the two control variables are decoupled and, therefore, the duty cycle control parameter has no direct effect on the regulation of the output voltage.

$$
\begin{aligned}
& G_{v_{o} \Phi}(s)=\left.\frac{\hat{v}_{O}(s)}{\hat{\Phi}(s)}\right|_{\hat{i}_{2}(s)=0}= \\
& =\frac{n V_{2} k+2(\Phi+\beta)^{2}\left(n V_{2}-V_{O}\right)}{(\Phi+\beta)} \cdot \frac{1}{s R_{L} C_{O} k+2 k+2 \Phi(\Phi+\beta)}
\end{aligned}
$$

In the same way, the audio susceptibility or line-to-output transfer function can be calculated as shown in (42).

$$
\begin{aligned}
& G_{v_{o} v_{2}}(s)=\left.\frac{\hat{v}_{O}(s)}{\hat{v}_{2}(s)}\right|_{\hat{\Phi}(s)=0}= \\
& =\frac{n \Phi k+2 n \Phi(\Phi+\beta)^{2}}{(\Phi+\beta)} \cdot \frac{1}{s R_{L} C_{O} k+2 k+2 \Phi(\Phi+\beta)}
\end{aligned}
$$

In order to ensure stability under all operating conditions, the dynamic behaviour of the TPC operating in the fully magnetized mode is also investigated. This operating mode is more complex than the completely demagnetized operation since no symmetry can be applied to the ac inductor waveform, as illustrated in Fig. 9.

As in the completely demagnetized operating mode, in the fully magnetized mode the state-variables are the rectified ac inductor current and the output capacitor voltage. The dynamic equation of the capacitor $C_{O}$ is expressed in terms of conservation of charge [36], [37] in order to take into account the correct charge applied to the output capacitor and accurately describe the dynamics involved in the rectified inductor current. By using the time intervals defined in (14) (20) the input and state matrices for the six time intervals can be written as (43). 


$$
\begin{aligned}
& A_{1}=\left[\begin{array}{cc}
0 & -\frac{1}{L_{a c}} \\
0 & \frac{\alpha T}{2 L_{a c} C_{O}}-\frac{1}{R_{L} C_{O}}
\end{array}\right] \quad A_{2}=\left[\begin{array}{cc}
0 & -\frac{1}{L_{a c}} \\
0 & \frac{(\Phi-\alpha) T}{2 L_{a c} C_{O}}-\frac{1}{R_{L} C_{O}}
\end{array}\right] \quad A_{3}=\left[\begin{array}{cc}
0 & -\frac{1}{L_{a c}} \\
0 & \frac{(D-\Phi) T}{2 L_{a c} C_{O}}+\frac{(\alpha-D+1 / 2) T}{L_{a c} C_{O}}-\frac{1}{R_{L} C_{O}}
\end{array}\right] \\
& A_{4}=\left[\begin{array}{cc}
0 & -\frac{1}{L_{a c}} \\
0 & \frac{(\alpha-D+1 / 2) T}{2 L_{a c} C_{O}}-\frac{1}{R_{L} C_{O}}
\end{array}\right] \quad A_{5}=\left[\begin{array}{cc}
0 & -\frac{1}{L_{a c}} \\
0 & \frac{(\Phi-\alpha+D-1 / 2) T}{2 L_{a c} C_{O}}-\frac{1}{R_{L} C_{O}}
\end{array}\right] \quad A_{6}=\left[\begin{array}{cc}
0 & -\frac{1}{L_{a c}} \\
0 & \frac{(1-D-\Phi) T}{2 L_{a c} C_{O}}+\frac{\alpha T}{L_{a c} C_{O}}-\frac{1}{R_{L} C_{O}}
\end{array}\right] \\
& B_{1}=\left[\begin{array}{c}
-\frac{n}{L_{a c}} \\
\frac{\alpha n T}{2 L_{a c} C_{O}}
\end{array}\right] \quad B_{2}=\left[\begin{array}{c}
\frac{n}{L_{a c}} \\
\frac{(\Phi-\alpha) n T}{2 L_{a c} C_{O}}
\end{array}\right] \quad B_{3}=\left[\begin{array}{c}
0 \\
\frac{n(\alpha-D+1 / 2) T}{2 L_{a c} C_{O}}
\end{array}\right] \\
& B_{4}=\left[\begin{array}{c}
-\frac{n}{L_{a c}} \\
\frac{n(\alpha-D+1 / 2) T}{2 L_{a c} C_{O}}
\end{array}\right] \quad B_{5}=\left[\begin{array}{c}
\frac{n}{L_{a c}} \\
\frac{(\Phi-\alpha+D-1 / 2) n T}{2 L_{a c} C_{O}}
\end{array}\right] \quad B_{6}=\left[\begin{array}{c}
0 \\
\alpha n T \\
2 L_{a c} C_{O}
\end{array}\right] \\
& A=A_{1} \alpha+A_{2}(\Phi-\alpha)+A_{3}(D-\Phi)+A_{4}(\alpha-D+1 / 2)+A_{5}(\Phi-\alpha+D-1 / 2)+A_{6}(1-D-\Phi) \\
& B=B_{1} \alpha+B_{2}(\Phi-\alpha)+B_{3}(D-\Phi)+B_{4}(\alpha-D+1 / 2)+B_{5}(\Phi-\alpha+D-1 / 2)+B_{6}(1-D-\Phi)
\end{aligned}
$$

The state and input matrices are averaged over a period, by using the time intervals defined in (14) - (20), as shown in (44) and (45). as

The system is linearized by using the Jacobian linearization

$$
\dot{\hat{x}}=A_{a l t} \hat{x}+B_{a l t} \hat{u}
$$

where the Jacobian matrices (47) are defined as the derivatives of the inductor and capacitor differential equations at the linearization point (48).

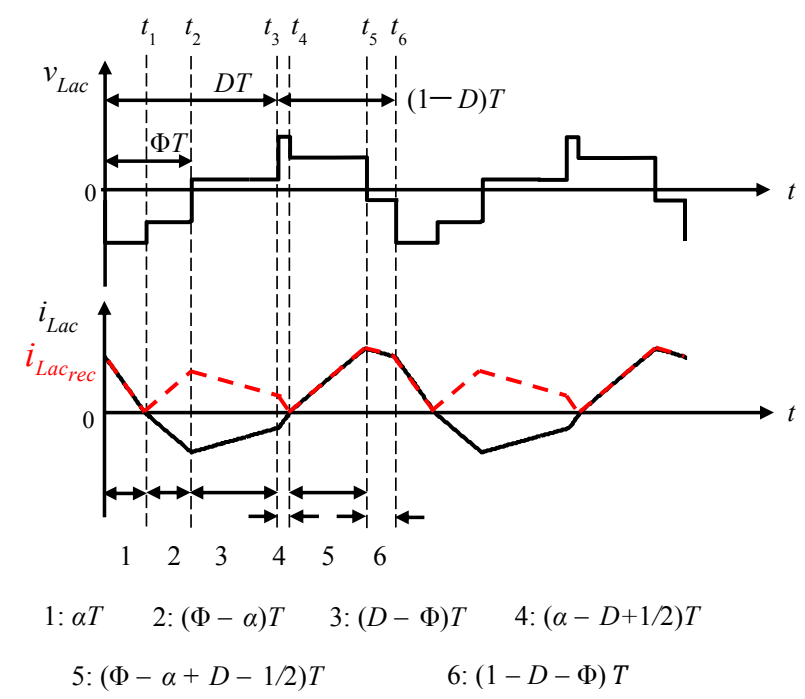

Fig. 9. Voltage and current across the ac inductor $L_{a c}$ (continuous) and rectified ac inductor current (dashed) in fully magnetized operation mode.

$$
A_{a l t}=\left.\left[\begin{array}{ll}
\frac{\partial f_{1}}{\partial i_{L_{a c}}} & \frac{\partial f_{1}}{\partial v_{C_{O}}} \\
\frac{\partial f_{2}}{\partial i_{L_{a c}}} & \frac{\partial f_{2}}{\partial v_{C_{O}}}
\end{array}\right]\right|_{\substack{i_{L_{a c}}=I_{L_{a c}} \\
v_{c_{o}}=V_{O}}}
$$

$$
\begin{gathered}
B_{a l t}=\left[\left.\begin{array}{l}
\frac{\partial f_{1}}{\partial u_{2}} \\
\frac{\partial f_{2}}{\partial u_{2}}
\end{array}\right|_{u_{2}=V_{2}} E_{a l t}=\left[\begin{array}{l}
\frac{\partial f_{1}}{\partial \Phi} \\
\frac{\partial f_{2}}{\partial \Phi}
\end{array}\right]_{\Phi=\Phi}\right. \\
{\left[\begin{array}{c}
\frac{d i_{L_{a c}}}{d t} \\
\frac{d v_{C_{O}}}{d t}
\end{array}\right]=\left[\begin{array}{ll}
A_{11} & A_{12} \\
A_{21} & A_{22}
\end{array}\right]\left[\begin{array}{l}
i_{L_{a c}} \\
v_{C_{O}}
\end{array}\right]+\left[\begin{array}{l}
B_{1} \\
B_{2}
\end{array}\right] u_{2}} \\
f_{1}=\frac{d i_{L_{a c}}}{d t}=A_{11} i_{L_{a c}}+A_{12} v_{C_{O}}+B_{1} u_{2} \\
f_{2}=\frac{d v_{C_{O}}}{d t}=A_{21} i_{L_{a c}}+A_{22} v_{C_{O}}+B_{2} u_{2}
\end{gathered}
$$

The state-variable-to-phase-shift transfer function is obtained as

$$
G_{x \Phi}(s)=\left.\frac{\hat{x}(s)}{\hat{\Phi}(s)}\right|_{\substack{\hat{u}_{2}(s)=0 \\ \hat{d}(s)=0}}=\left[s I-A_{a l t}\right]^{-1} \cdot E_{\text {alt }}
$$


In the same way, by using (46) to (49) and calculating the partial derivatives respect to the duty cycle instead of the phase-shift, the duty-cycle-to-output voltage transfer function for the fully magnetized operation mode can be obtained.

\section{B. State-Space Modelling of the Bidirectional Interleaved Boost Converter (BIBC)}

In this section, state-space modelling of the $\mathrm{BIBC}$, which operates in continuous conduction mode (CCM), is performed. The circuit diagram of the converter is shown in Fig. 10. The input ports, $V_{1}$ and $V_{2}$, interface with the renewable energy source and energy storage, respectively. Hence, the primary side of the proposed topology can be seen as an interleaved boost or buck converter depending on the direction of the power flow. In the case of a photovoltaic (PV) panel as the renewable energy source, the control variable will be taken as the converter input voltage, since the PV voltage does not present strong variations with irradiation changes [38]. In the case of a fuel cell, input current control will be selected in order to operate the fuel cell at a constant load level. Moreover, the parameters of the energy storage port can be monitored and the control scheme changed to voltage or current control on the battery depending on its state of charge (SOC).

The state-space modelling of the BIBC is performed with ideal components; nevertheless, both ports $V_{1}$ and $V_{2}$, are modelled as an ideal voltage source with a series resistance in order to account for the dynamic resistance of the renewable energy source or the energy storage element. The state-space vector is chosen as $x=\left[\begin{array}{lll}i_{L} & v_{C_{1}} & v_{C_{2}}\end{array}\right]^{T}$. The converter presents two switching intervals depending on the position of the switches $M_{2}$ and $M_{4}$. The state, input, output and direct transmission matrices, $A, B, C, D$, respectively, for each subinterval (50), (51), are averaged over a period by multiplying by each switching interval duty cycle, (52) and expressed in terms of the state-space equation, as shown in (53) and (54).

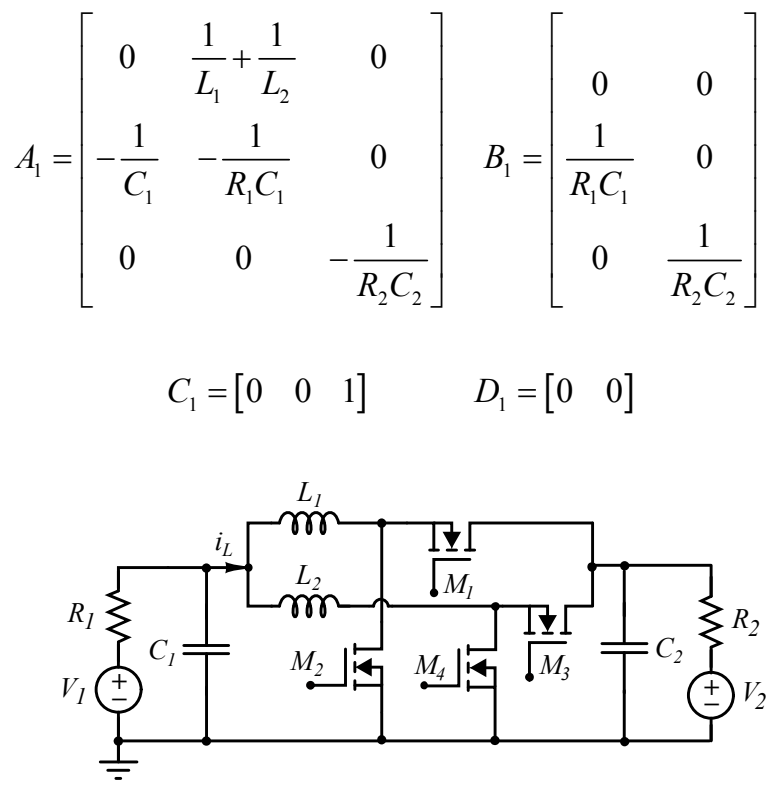

Fig. 10. Bidirectional interleaved boost converter BIBC.

$$
\begin{aligned}
& A_{2}=\left[\begin{array}{ccc}
0 & \frac{1}{L_{1}}+\frac{1}{L_{2}} & -\frac{1}{L_{1}}-\frac{1}{L_{2}} \\
-\frac{1}{C_{1}} & -\frac{1}{R_{1} C_{1}} & 0 \\
\frac{1}{C_{2}} & 0 & -\frac{1}{R_{2} C_{2}}
\end{array}\right] B_{2}=\left[\begin{array}{cc}
0 & 0 \\
\frac{1}{R_{1} C_{1}} & 0 \\
0 & \frac{1}{R_{2} C_{2}}
\end{array}\right] \\
& C_{2}=\left[\begin{array}{lll}
0 & 0 & 1
\end{array}\right] \quad D_{2}=\left[\begin{array}{ll}
0 & 0
\end{array}\right] \\
& A=A_{1} D+A_{2}(1-D) \\
& B=B_{1} D+B_{2}(1-D) \\
& C=C_{1} D+C_{2}(1-D) \\
& D=D_{1} D+D_{2}(1-D) \\
& \dot{x}=A x+B u \\
& y=C x+D u
\end{aligned}
$$

After the perturbation and linearization, the duty-cycle to state-variable (55) and the steady-state (dc) operating point (56) are obtained. From (55), the controllers for voltage and current regulation of the renewable energy and the energy storage port can be designed accordingly.

$$
\begin{gathered}
\hat{x}=(s I-A)^{-1} \cdot\left[\left(A_{1}-A_{2}\right) X+\left(B_{1}-B_{2}\right) U\right] \\
X=-A^{-1} \cdot B \cdot U
\end{gathered}
$$

The audio susceptibility transfer function is calculated as (57).

$$
G_{v_{2} v_{1}}(s)=\left.\frac{\hat{v}_{2}(s)}{\hat{v}_{1}(s)}\right|_{\hat{d}(s)=0}=C(s I-A)^{-1} \cdot B
$$

In the BIBC, the variation of the phase-shift angle will only affect the input current ripple; therefore, it does not have an effect on the averaged current, and consequently, on the dutycycle-to-inductor current transfer function.

\section{Power Flow Regulation AND CONTROL}

The block diagram of the designed power management and feedback regulators is shown in Fig. 11. Four different controllers are designed for the energy management of the renewable power system. At the renewable energy port, either voltage or current can be selected to be regulated depending on the type of the selected renewable energy source. At the energy storage port, constant voltage (CV) and constant current $(\mathrm{CI})$ regulators are implemented, and at the output port, voltage regulation is performed. In order to control the power among the two inputs and the load and thereby balance the power between the different energy sources, two control loops are active at any time. The output port regulation loop is employed to regulate the load voltage by the phase-shift angle $\Phi$. On the other hand, assuming $V_{1}$ is the renewable energy source such as fuel cells or photovoltaics, the voltage or current is controlled by the duty cycle $D$. The power from the other input $V_{2}$ as an energy storage unit, for example a battery or a super-capacitor, is controlled depending on the power at the renewable energy source and the output load power 


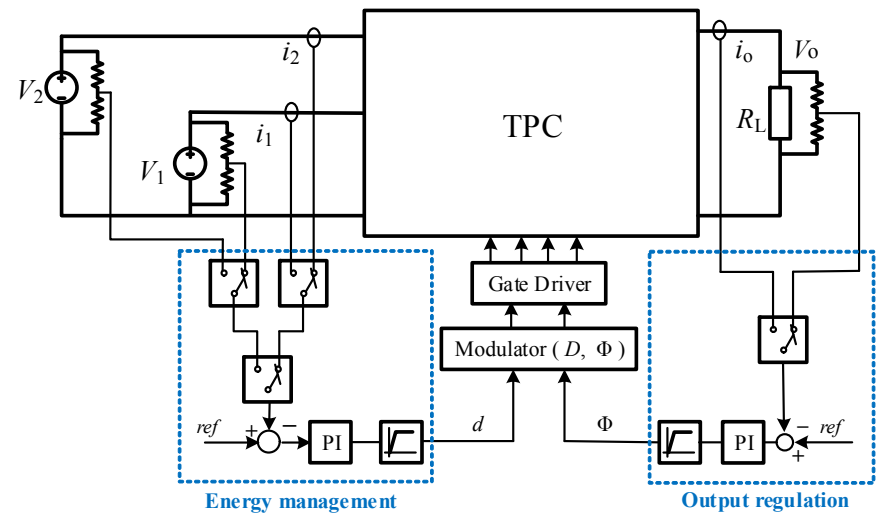

Fig. 11. Block diagram of energy/power management and control.

demand. Therefore, the energy management and control scheme can be summarized in the following way. The system is always set to control the renewable energy source and in the case of a photovoltaic application, to maximize the power delivered to the system through a maximum power point tracking algorithm (MPPT). If the renewable input power is smaller than the required power at the output port, the storage unit will compensate the power difference automatically. On the other hand, if the input power is bigger than the power required at the load terminal, the energy surplus is used to charge the energy storage element by inverting the power flow direction at this port. The state-of-charge (SOC) of the energy storage element is always being monitored and when it is above or below its recommended values, the system is set to control the bidirectional port by performing CV or CI control, until the energy storage element SOC allows for a change in the operation mode.

\section{EXPERIMENTAL RESULTS}

The proposed TPC has been simulated, designed, built and tested to validate the previous theoretical analysis including the derived small-signal models. Fig. 12 shows the experimental prototype of the proposed TPC topology, which is constructed with a fast prototyping technique. The converter is designed to interface with hybrid renewable energy systems, i.e operating a single phase grid-tie or as stand-alone dc microgrid power system. The specifications and the components employed in the construction of the prototype are listed in Table I. The control law is implemented by means of a digital signal processor (DSP) TMS320F28035 to generate the four gate signals with an adjustable duty cycle and phaseshift angle. The currents at the input and output ports are measured with Hall Effect current transducers LEM LA55-P, LA25-NP respectively.

Fig. 13 illustrates the measured waveforms of the PWM signal $v_{G S-M 2}$ and $v_{G S-M 4}$ and the two phase-shifted inductor currents $i_{L 1}$ and $i_{L 2}$.

According to the waveforms of ZVS operation shown in Fig. 14 , the drain to source voltage $v_{D S-M 3}$ and $v_{D S-M 4}$ have completely decreased to zero before switches $M_{3}$ and $M_{4}$ are turned-on, and there are no transient voltage spikes and rings across the switches. Therefore, the converter will have close to zero switching losses and low electromagnetic emissions.

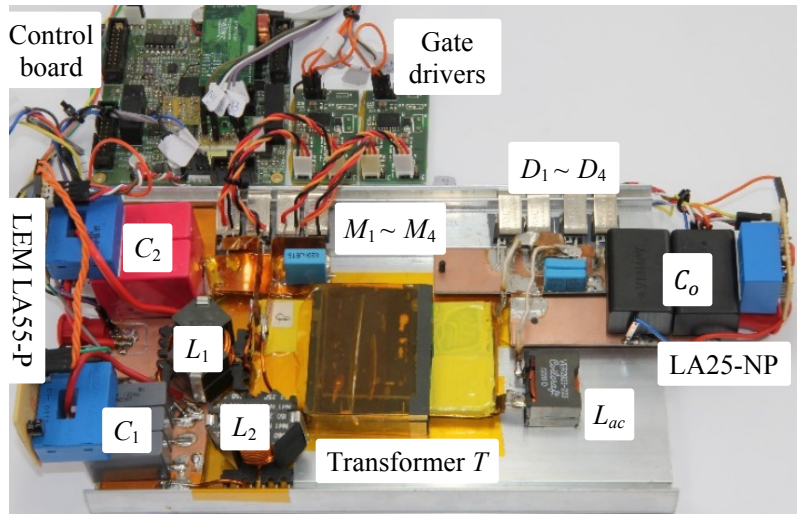

Fig. 12. Experimental prototype of the proposed TPC topology.

TABLE I

SYSTEM SPECIFICATIONS AND COMPONENTS

\begin{tabular}{cc}
\hline \hline \multicolumn{2}{c}{ SYSTEM SPECIFICATIONS AND COMPONENTS } \\
\hline Input voltage & $V_{1}=25-60 \mathrm{~V}$ \\
Output voltage & $V_{2 \max }=120 \mathrm{~V}$ \\
Maximum output power & $V_{\mathrm{O}}=300 \sim 380 \mathrm{~V}$ \\
$P_{\mathrm{O} \max } \sim 1000 \mathrm{~W}$ \\
$D_{1} \sim D_{4}$ & IRFB4115 $(150 \mathrm{~V} / 104 \mathrm{~A})$ \\
Transformer $T$ & $4: 16$, ELP $64 / 10 / 50$ Ferrite N 87 \\
Inductors $L_{1}$ and $L_{2}$ & $155 \mu H \mathrm{~N} 41$ gapped core RM12 \\
Inductor $L_{a c}$ & $28 \mu H$ Coilcraft VER2923-223 \\
Capacitor $C_{1}$ & $2 \times 10 \mu \mathrm{F} 160 \mathrm{~V}$ WIMA MKP4 \\
Capacitor $C_{2}$ & $3 \times 22 \mu \mathrm{F} 63 \mathrm{~V}$ AV MKT \\
Capacitor $C_{0}$ & $2 \times 10 \mu \mathrm{F} \mathrm{700} \mathrm{V} \mathrm{VISHAY} \mathrm{MKP}$ \\
Switching frequency & $f=60 \mathrm{kHz}$ \\
Digital controller & $\mathrm{TMS} 320 \mathrm{~F} 28035 \mathrm{DSP}$ \\
\hline \hline
\end{tabular}

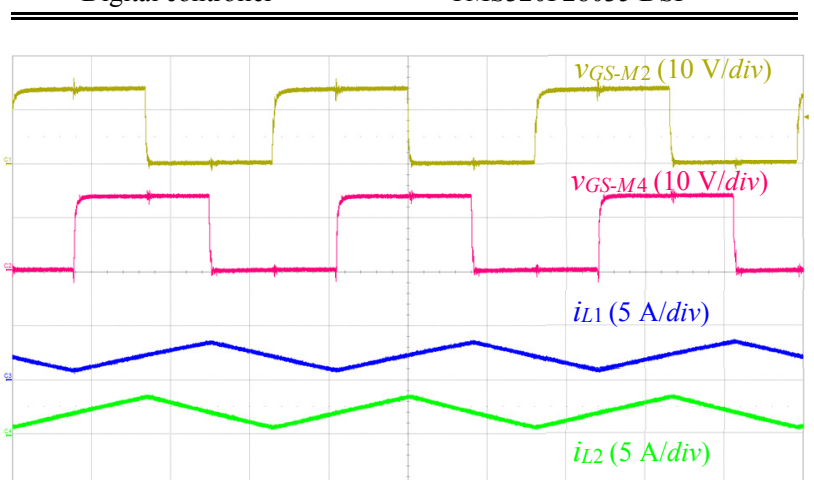

Fig. 13. Experimental results of the phase-shifted gate-source voltage of $M_{2}$ and $M_{4}$ and the inductor currents $i_{L 1}$ and $i_{L 2}$ operating in DI mode at $V_{1}=50 \mathrm{~V}$, $V_{2}=100 \mathrm{~V}$ and $V_{O}=370 \mathrm{~V}, P_{O}=400 \mathrm{~W}, P_{1}=200 \mathrm{~W}, P_{2}=200 \mathrm{~W}$. Time scale: $5 \mu \mathrm{s} / \mathrm{div}$.

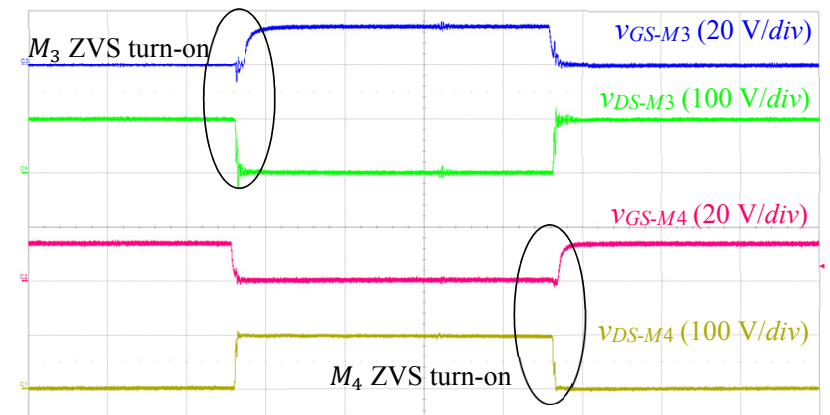

Fig. 14. Experimental results of the gate voltage and drain voltage of $M_{3}$ and $M_{4}$ at $V_{1}=50 \mathrm{~V}, V_{2}=100 \mathrm{~V}$ and $V_{O}=370 \mathrm{~V}, P_{1}=100 \mathrm{~W}, P_{2}=100 \mathrm{~W}, P_{O}=$ $200 \mathrm{~W}$. Time scale: $2 \mu$ s/div. 


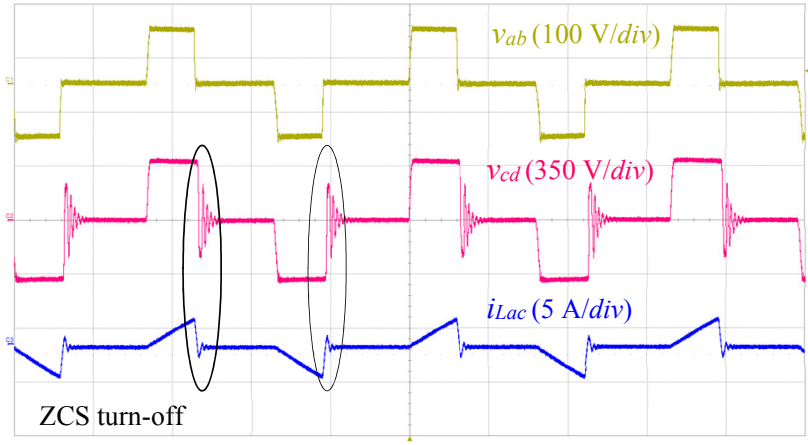

(a)

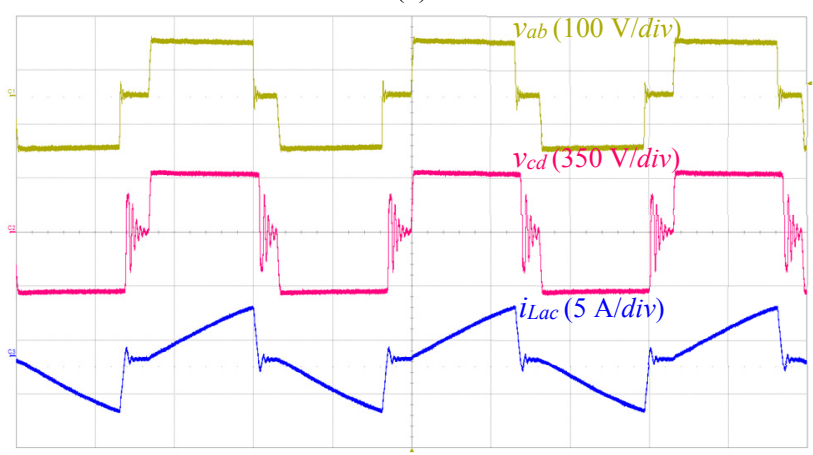

(b)

Fig. 15. Experimental results of the high frequency ac voltages $v_{a b}, v_{c d}$ and inductor current $i_{L a c}$ operating in DI mode at $V_{1}=50 \mathrm{~V}, V_{2}=100 \mathrm{~V}$ and $V_{O}=$ $370 \mathrm{~V}(a) P_{O}=200 \mathrm{~W}, P_{1}=100 \mathrm{~W}, P_{2}=100 \mathrm{~W}$. (b) $P_{O}=800 \mathrm{~W}, P_{1}=100 \mathrm{~W}$, $P_{2}=700 \mathrm{~W}$. Time scale: $5 \mu \mathrm{s} /$ div.

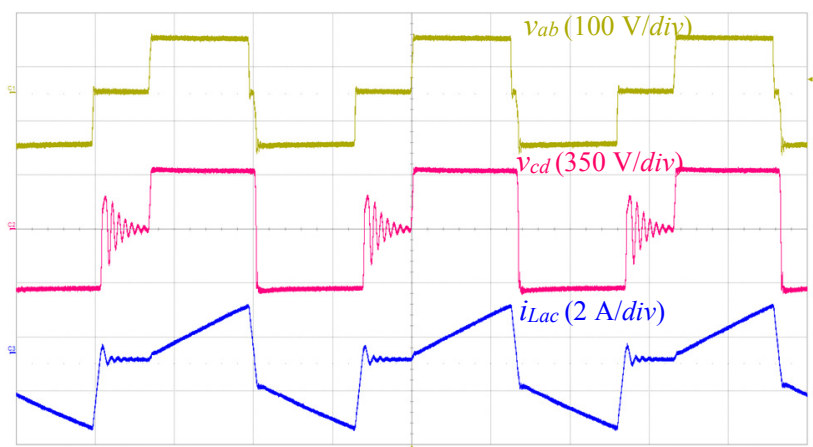

Fig. 16. Experimental waveforms of $v_{a b}, v_{c d}$ and partially magnetized $i_{L a c}$ operating in DI mode at $V_{1}=40 \mathrm{~V}, V_{2}=100 \mathrm{~V}$ and $V_{O}=370 \mathrm{~V}, P_{1}=100 \mathrm{~W}, P_{2}$ $=300 \mathrm{~W}, P_{O}=400 \mathrm{~W}$. Time scale: $5 \mu s / d i v$.

Fig. $15(a)$ and $(b)$ shows the measured high frequency ac voltages $v_{a b}, v_{c d}$ and inductor current $i_{L a c}$ of the converter operating in DI mode at different output power levels, respectively. It can be found that by using the capacitor $C_{2}$ and high side switches $M_{1}$ and $M_{3}$ as an active clamp circuit, the voltage transient spike across the current-fed bridge is suppressed.

The ZCS operation of the output diodes can be observed in the high frequency ac voltage $v_{L a c}$ and current $i_{L a c}$ shown in Fig. 15. As discussed in section III, due to the use of an ac inductor, the output bridge rectifier always changes its conduction state when the ac inductor current reaches zero, and therefore, the diodes always turn-off under ZCS conditions. A high frequency oscillation in the ac voltage $v_{c d}$ can also be observed in Fig. 15. As in any discontinuous conduction mode (DCM) converter operation, when the inductor current reaches zero, a resonance between the bridge rectifier parasitic capacitance and the ac inductor magnetizing inductance occurs. The energy stored in the diodes' parasitic capacitance will be dissipated in the circuit as joule losses. This loss, independent of the converter output power, is calculated to be $16 \mathrm{~mW}$, for $V_{D}=V_{O}=380 \mathrm{~V}$, according to the junction capacitance value given in the component's datasheet.

As an example, if a larger ac inductor is used $(66 \mu \mathrm{H})$, the ac inductor current becomes partially magnetized. The experimental waveforms in this operating mode are presented in Fig. 16, where it can be seen that the ac inductor current does not stay at zero level before starting the next charging subinterval, as in the key operating waveform shown in Fig. 4.

Fig. $17(a)$ and $(b)$ shows the measured efficiency curves of the TPC topology operating in DI, DO and SISO modes at $V_{1}$ $=50 \mathrm{~V}, V_{2}=100 \mathrm{~V}$ and $V_{O}=370 \mathrm{~V}$. The efficiency measurement is performed with the converter operating in closed loop with a dc power supply connected in parallel to an electronic load at the bidirectional port. The electronic load is configured in constant voltage (CV) mode to simulate the behaviour of a battery. As it can be observed, when the converter operates in DO mode, the efficiency increases as the power flow moves from the output port (SISO $V_{1} V_{O}$ ) towards the bidirectional port (SISO $V_{1} V_{2}$ ). This is due to the fact that the energy is processed only by the non-isolated interleaved boost converter instead of being boosted to $V_{2}$ and transferred through the transformer to the output port $V_{O}$. A peak

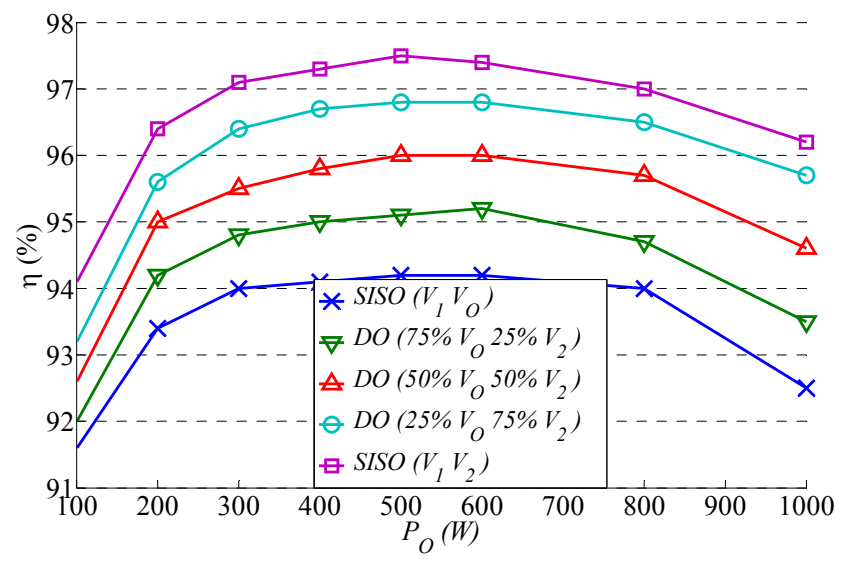

(a)

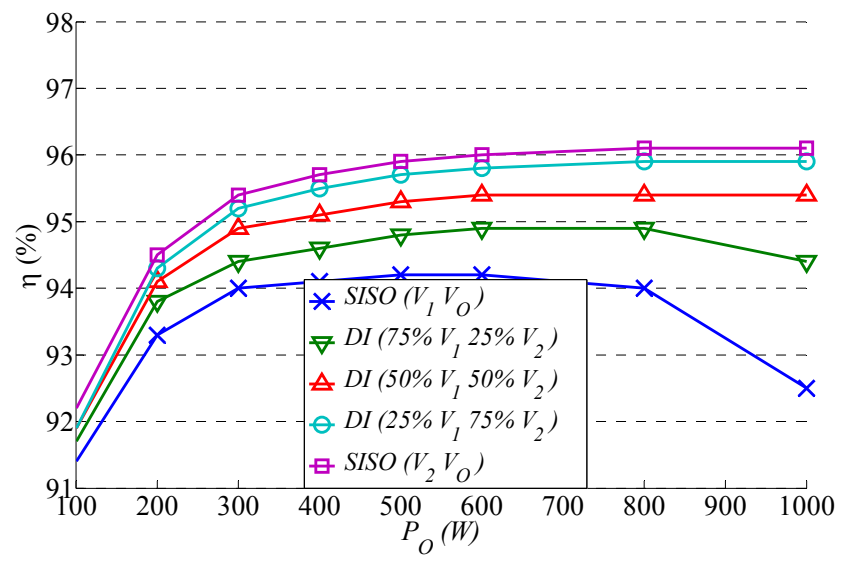

(b)

Fig. 17. Measured efficiency curves of the converter in DI, DO and SISO modes at $V_{1}=50 \mathrm{~V}, V_{2}=100 \mathrm{~V}$ and $V_{O}=370 \mathrm{~V}$. 
efficiency of $97.5 \%$ is achieved in SISO $V_{1} V_{2}$, whereas the maximum achieved efficiency in SISO $V_{1} V_{O}$ mode is $94.2 \%$. The same behavior is observed when the converter operates in DI mode and the operation changes from SISO $V_{1} V_{O}$ to SISO $V_{2} V_{O}$. In this case, SISO $V_{2} V_{O}$ shows higher efficiency than SISO $V_{1} V_{O}$ due to the energy being processed once through the phase-shift isolated stage instead of being boosted from $V_{1}$ to $V_{2}$ and then transferred to the output through the isolated stage. The maximum efficiency achieved in SISO $V_{2} V_{O}$ mode is $96.1 \%$.

In order to validate the mathematical modelling performed in section IV, the calculated control and input transfer functions are compared to LTspice simulations [34], [35], as well as experimental measurements. The dynamic behaviour of the TPC is measured with a vector network analyser (VNA) OmicronLab Bode100. Fig. 18 shows the calculated, simulated and measured phase-shift-to-output voltage transfer function of the PSFB converter operating in completely demagnetized mode under the following conditions: $V_{2}=50$ $\mathrm{V}, V_{O}=100 \mathrm{~V}, R_{L}=100 \Omega, P_{O}=100 \mathrm{~W}, \Phi=0.17 \pi$. As it can be observed, the mathematical model shows very good match with the simulation and the experimental results.

As in the completely demagnetized mode, in order to validate the mathematical model of the PSFB operating in fully magnetized operation, the circuit is simulated in LTspice and the result is compared to the mathematical model, as shown in Fig. 19. The simulation and the calculation are performed under the following conditions: $V_{2}=50 \mathrm{~V}, V_{O}=$ $100 \mathrm{~V}, R_{L}=10 \Omega, P_{O}=1000 \mathrm{~W}, \Phi=0.74 \pi, D=0.6$. As it can be observed, in the fully magnetized mode, the system behaves as a first order system, since the inductor current dynamics contributes very little to the control-to-output transfer function. This is due to the fact that the inductor current is an ac waveform, which makes the dynamics of this state-variable only visible at high frequencies. The control-tooutput transfer function in fully magnetized mode is, therefore similar to the demagnetized operation; however, in this case, the gain is reduced due to the increased output load. As observed in Fig. 19, the proposed mathematical model shows good match with the simulation results. On the other hand, the duty cycle-to-output voltage transfer function gain is several

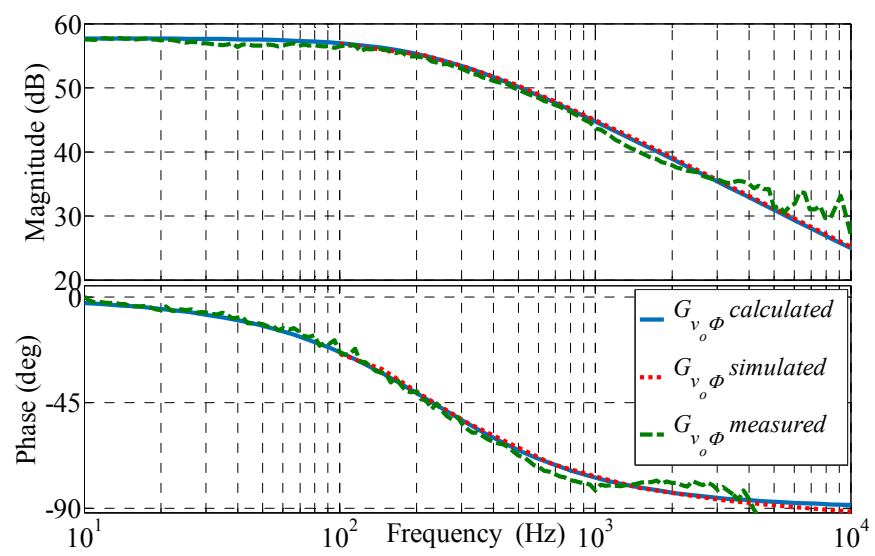

Fig. 18. PSFB completely demagnetized ac inductor current phase-shift-tooutput voltage $\left(G_{v_{o} \Phi}\right)$ transfer function calculated (continuous line), simulated (dotted line) and measured (dashed line).

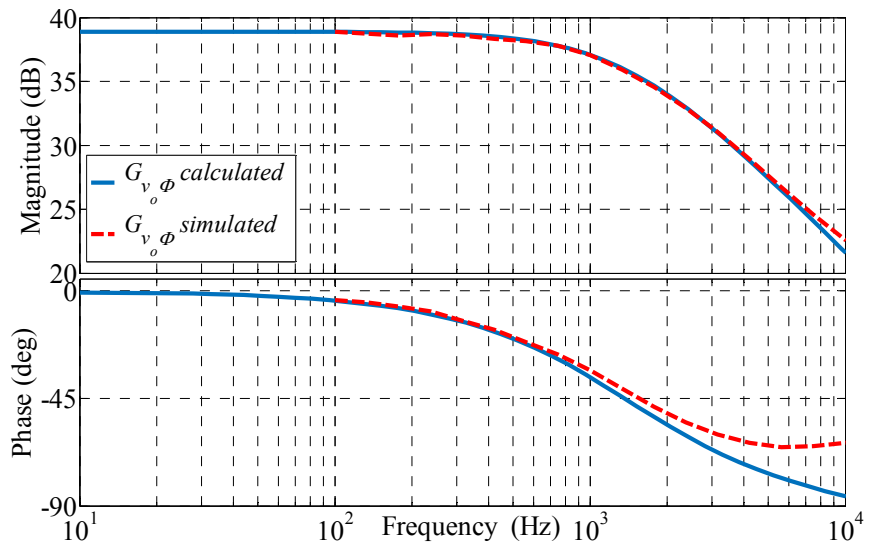

Fig. 19. PSFB fully magnetized ac inductor current phase-shift-to-output voltage $\left.\left(G_{v_{o}} \Phi\right)\right)$ transfer function calculated (continuous line) and measured (dashed line).

orders of magnitude smaller than the phase-shift-to-output voltage transfer function gain. Therefore, the perturbations on the duty cycle due to the regulation of the power flow between $V_{1}$ and $V_{2}$, will have very small effect on the regulation of the converter output voltage. Since the plant transfer function behaves similarly to the demagnetized mode, and no special consideration need to be taken into account to suppress perturbations due to variations in the converter duty cycle, it can be concluded that entering this mode will not present any stability issues.

Once the validity of the model is verified, a compensation for the PSFB converter operating in completely demagnetized mode is designed. The compensation consists of an integrator and a zero placed at the resonant frequency of the plant transfer function. Fig. 20 shows the PSFB converter calculated and measured loop-gain for the designed controller with a crossover frequency of $f_{\mathrm{c}}=2.29 \mathrm{kHz}$ and phase margin $\mathrm{PM}=$ $40^{\circ}$. As it can be observed in Fig. 20, the loop gain measurement presents very close match with the mathematical calculation.

As in the PSFB case, in order to validate the mathematical modelling of the BIBC duty-cycle-to-inductor current transfer measurement is performed with the converter working with a

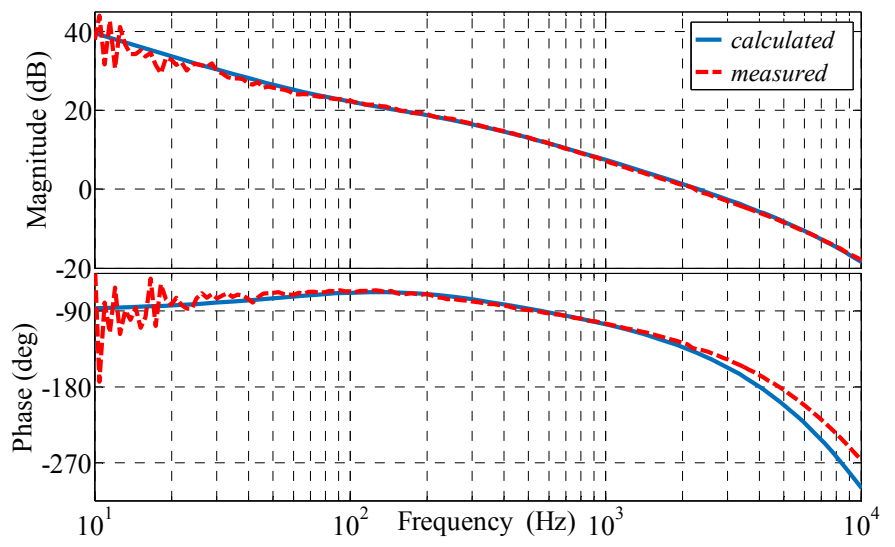

Fig. 20. PSFB completely demagnetized ac inductor current phase-shift-tooutput voltage loop-gain transfer function calculated (continuous line) and measured (dashed line). 
resistive load instead of with an electronic load configured in CV mode. Measuring any transfer function with an electronic load is not recommended since the control circuit of the electronic load can interfere with the converter under test. Notice that the BIBC plant transfer function differs when is operated with a battery or with a resistive load. This can be observed from the calculated and simulated duty-cycle-toinductor current transfer function shown in Fig. $21(a)$ for battery load, and the measured transfer function with a resistive load, shown Fig. 21 (b), for the same converter power level. The complex poles appearing at the converter natural resonant frequency in the resistive load case are split in the case of battery loading, which make the battery load case to behave as a first order system. Fig. 21 (a) shows the calculated and simulated duty-cycle-to-inductor current transfer function with a battery as a load under the following operating conditions: $V_{1}=25 \mathrm{~V}, R_{1}=150 \mathrm{~m} \Omega, V_{2}=50 \mathrm{~V}, R_{2}=25 \Omega$, $I_{L}=4 \mathrm{~A}, P_{2}=100 \mathrm{~W}, D=0.513$. Fig. $21(b)$ shows the measurement of the BIBC duty-cycle-to-inductor current transfer function with resistive load under the following conditions: $V_{1}=25 \mathrm{~V}, R_{1}=150 \mathrm{~m} \Omega, V_{2}=50 \mathrm{~V}, R_{2}=100$ $\mathrm{m} \Omega, I_{L}=4 \mathrm{~A}, P_{2}=100 \mathrm{~W}, D=0.513$. As it can be observed from the results presented in Fig. 21, the mathematical model shows very good match with the performed simulation and measurement. A compensation for the BIBC operating with a battery at the bidirectional port $V_{2}$ is designed. The compensation consisting of an integrator and a zero is designed and tested; nevertheless, the measurement results are not shown due to the aforementioned reasons.

The audio susceptibilities of the separate converters as well as the combination as a TPC topology are investigated. The audio susceptibility, or line-to-output transfer function, relates how variations at the input port will affect the output as a function of the frequency; hence, the interaction between the two control loops within the proposed topology can be examined. Fig. $22(a)$ and $(b)$ present the calculated and measured audio susceptibility transfer functions of the PSFB converter and the BIBC, respectively, under the conditions: $V_{1}$ $=25 \mathrm{~V}, R_{1}=150 \mathrm{~m} \Omega, V_{2}=50 \mathrm{~V}, R_{2}=50 \Omega, I_{L}=2 \mathrm{~A}, P_{2}=50$ $\mathrm{W}, D=0.513$, where a Picotest J2120 is used to inject up to 50 $\mathrm{V}$ input voltage and $5 \mathrm{~A}$ input current. As it can be observed the measurements show close match with the proposed model.

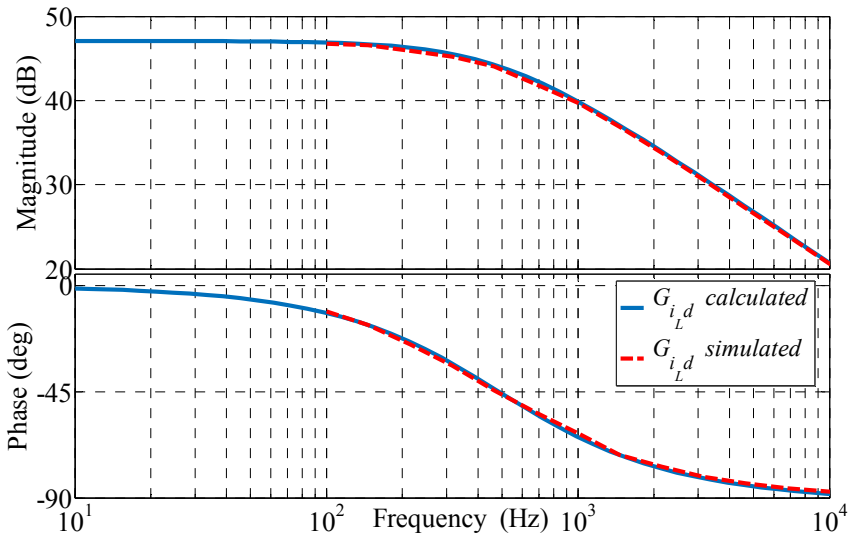

(a)

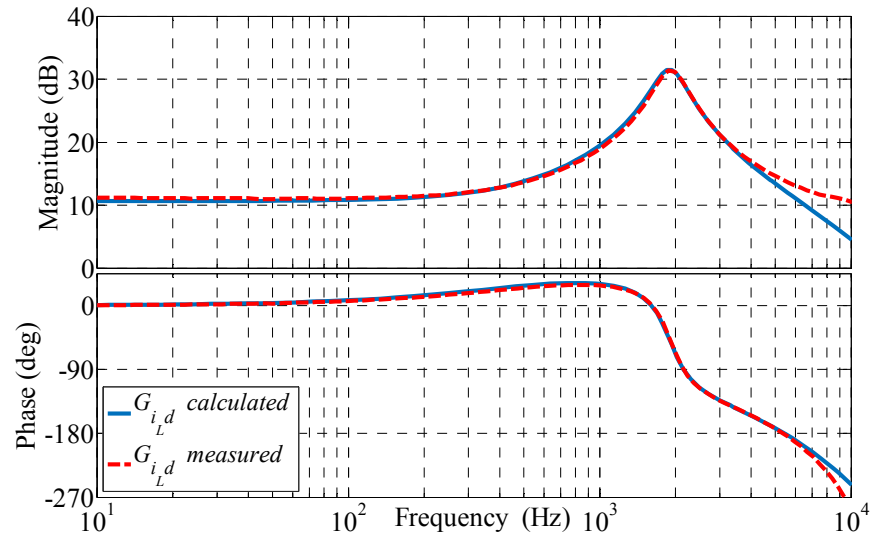

(b)

Fig. 21. BIBC duty-cycle-to-inductor current $\left(G_{i_{L} d}\right)$ transfer function: $(a)$ operated with a battery as a load calculated (continuous line) and simulated (dashed line) and $(b)$ operated with a resistive load, calculated (continuous line) and measured (dashed line).

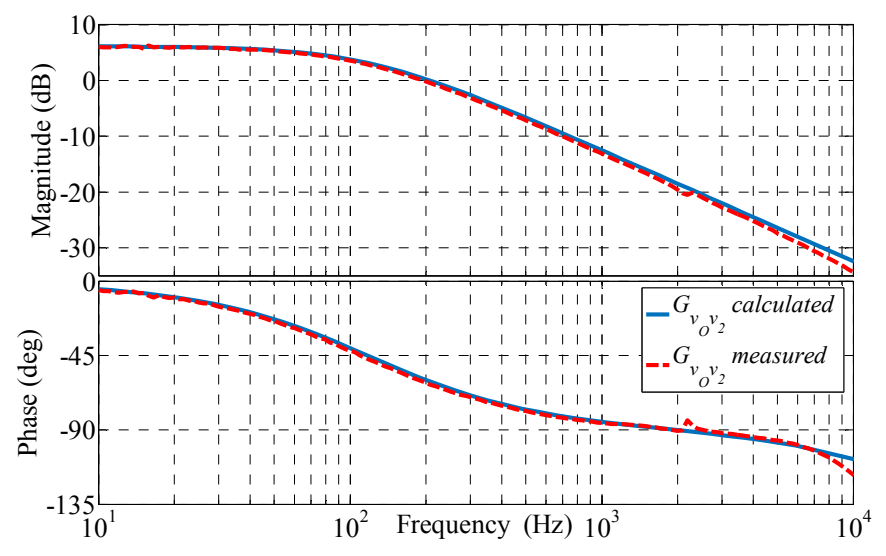

(a)

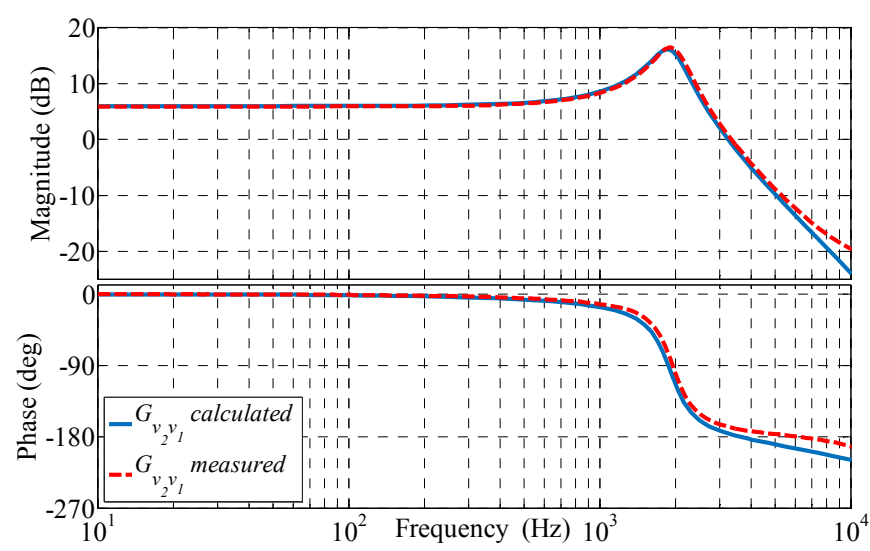

(b)

Fig. 22. Calculated (continuous line) and measured (dashed line) audio susceptibility transfer functions: $(a)$ PSFB audio susceptibility $\left(G_{v_{0} v_{2}}\right),(b)$ BIBC audio susceptibility $\left(G_{v_{2} v_{1}}\right)$. 


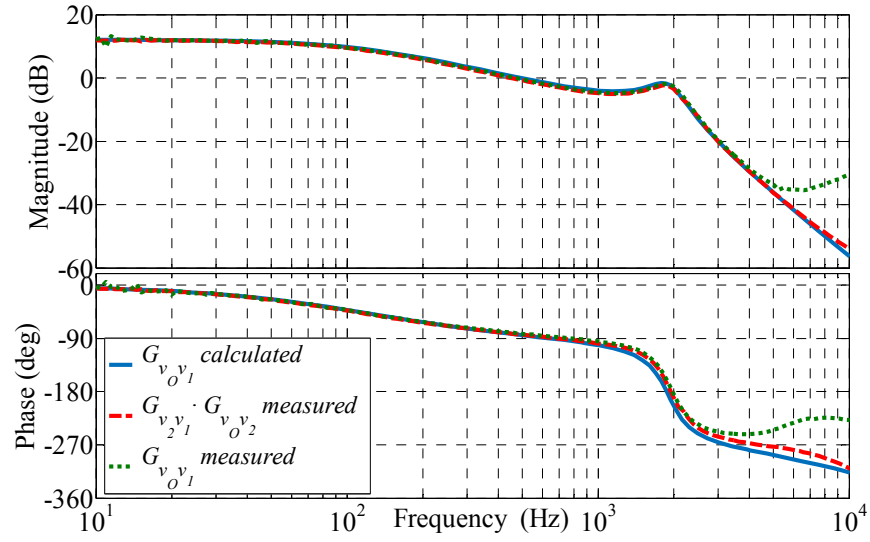

Fig. 23. Calculated (continuous line) and measured (dashed lines) TPC audio susceptibility $\left(G_{v_{o} v_{1}}\right)$ transfer function.

Fig. 23 shows the calculated and measured line-to-output transfer function of the TCP (from the input port $V_{1}$ to the output port $V_{\mathrm{O}}$ ), measured under the following conditions: $V_{1}$ $=25 \mathrm{~V}, R_{1}=150 \mathrm{~m} \Omega, V_{2}=50 \mathrm{~V}, R_{2}=50 \Omega, I_{L}=2 \mathrm{~A}, P_{2}=50$ $\mathrm{W}, D=0.513, V_{O}=100 \mathrm{~V}, R_{L}=200 \Omega, P_{O}=50 \mathrm{~W}, \Phi=$ $0.17 \pi$. The calculated transfer function is obtained as the series combination of the individual transfer functions (58).

$$
G_{v_{o} v_{1}}(s)=G_{v_{2} v_{1}}(s) \cdot G_{v_{o} v_{2}}(s)=\left.\left.\frac{\hat{v}_{2}(s)}{\hat{v}_{1}(s)}\right|_{\hat{d}(s)=0} \cdot \frac{\hat{v}_{o}(s)}{\hat{v}_{2}(s)}\right|_{\hat{\Phi}(s)=0}
$$

As it can be observed in Fig. 23, the measurement of the audio susceptibility from the input port $V_{1}$ to the output port $V_{O}$ matches with the calculated transfer function where the system dynamic behavior is modelled as two separate converters. From this measurement, it can be concluded that the converter output voltage $V_{O}$ is not directly affected by perturbations on the converter input port $V_{1}$ or the duty cycle, but by the effect of these on the converter bidirectional port voltage $V_{2}$. Therefore, as discussed in the converter modelling section, from a control point of view the proposed TPC effectively behaves as two separate converters to regulate the two power flows.
The performance of the proposed energy management system and control loops is verified by different experimental measurements [39]. Fig. 24 and Fig. 25 show the input currents of both of the converter input ports, $I_{1}$ and $I_{2}$, as well as the load current, $I_{O}$, and the output voltage $V_{O}$. The converter is operating at $V_{1}=50 \mathrm{~V}, V_{2}=100 \mathrm{~V}$ and $V_{O}=370$ V. Fig. $24(a)$ to (e) shows the transition between different operating modes due to variations of the available power at the renewable energy port, while the load demand remains constant $\left(P_{O}=250 \mathrm{~W}\right)$. Depending on the available power at the renewable energy port, the converter operating mode changes between DI mode, DO mode and SISO $V_{1}$ as illustrated in Table II. As it can be observed from the transitions shown in Fig. 24, variations of the power at the renewable energy port does not affect the voltage regulation at the output port, since the duty cycle control variable does not have an effect on the output voltage regulation when the converter operates in completely demagnetized mode.

In the same way, the transitions between different operating modes due to variations of the output port load demand are tested. Fig. $25(a)$ to $(f)$ shows the transition between different operating modes due to variations of the output power, while the power at the renewable energy port remains constant $\left(P_{1}=\right.$ $250 \mathrm{~W})$. Depending on the load demand, the converter operating mode changes between SISO $V_{1}$, DI mode and DO mode, as presented in Table III. As it can be observed from

TABLE II

POWER AT THE PORTS FOR TRANSITIONS BETWEEN OPERATING MODES UNDER CONSTANT OUTPUT LOAD

\begin{tabular}{ccccc}
\hline \hline & SISO $V_{1}$ & SISO $V_{2}$ & DI & DO \\
$P_{1}(W)$ & 250 & 0 & 125 & 375 \\
$P_{2}(W)$ & 0 & 250 & 125 & -125 \\
$P_{O}(W)$ & 250 & 250 & 250 & 250 \\
\hline \hline
\end{tabular}

TABLE III

POWER AT THE PORTS FOR TRANSITIONS BETWEEN OPERATING MODES UNDER CONSTANT POWER AT THE RENEWABLE ENERGY SOURCE

\begin{tabular}{cccc}
\hline \hline & SISO $V_{1}$ & DI & DO \\
$P_{1}(W)$ & 250 & 250 & 250 \\
$P_{2}(W)$ & 0 & 125 & -125 \\
$P_{O}(W)$ & 250 & 375 & 125 \\
\hline \hline
\end{tabular}

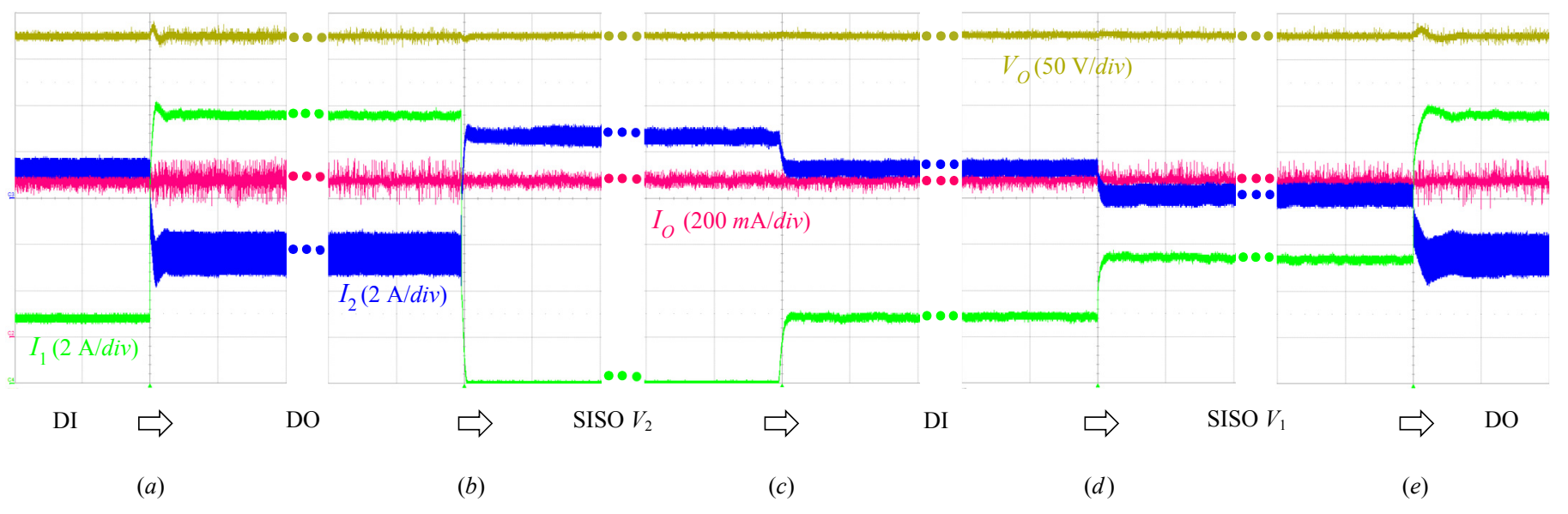

Fig. 24. Transition between different operating modes due to variations of the available power at the renewable energy port. Time scale: $20 \mathrm{~ms} / \mathrm{div}$. 


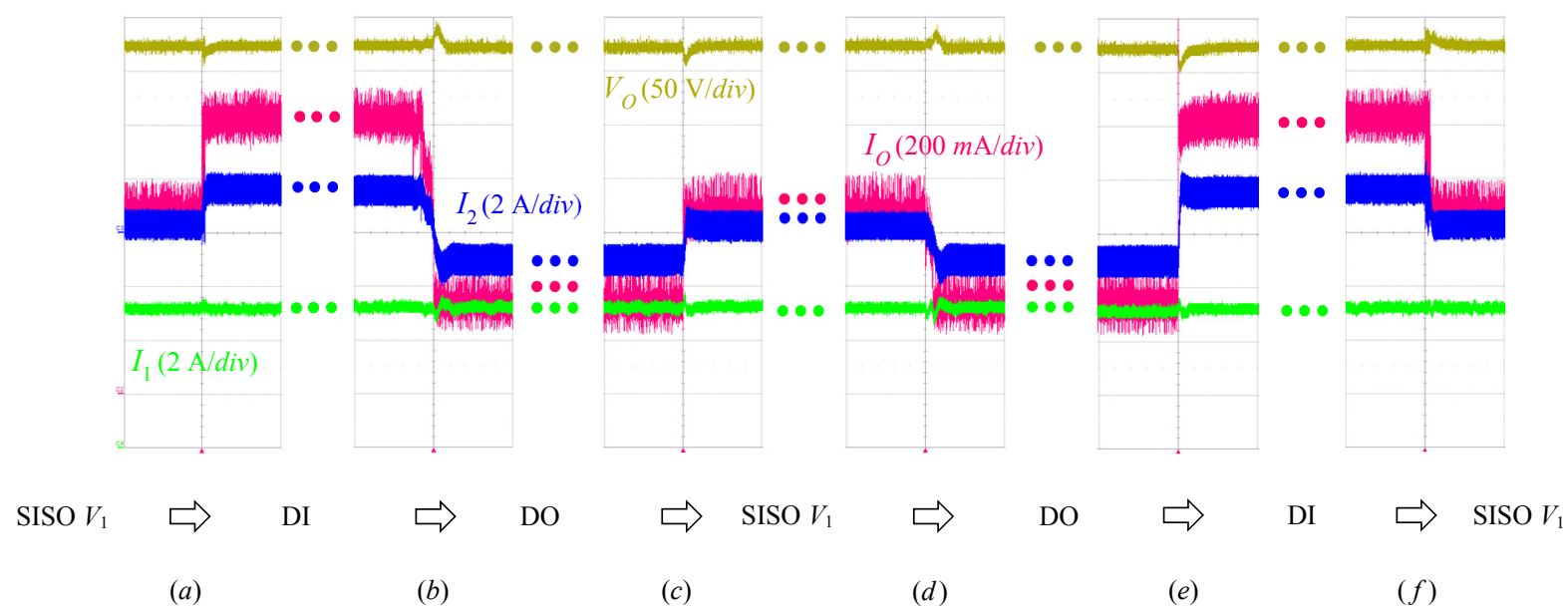

Fig. 25. Transition between different operating modes due to variations of the output port load demand. Time scale: $50 \mathrm{~ms} / \mathrm{div}$.

the different load steps in Fig. 25, variations of the output power do not affect the current at the renewable energy port, since the phase-shift control loop is decoupled from the duty cycle regulation that controls the power flow from the renewable energy source. Therefore, the power at the renewable energy port can be fully controlled, while the voltage at the output port is regulated, and the energy storage will compensate for the load dynamics. A disturbance in the output voltage $V_{O}$ in Fig. 24 and in the input current $I_{1}$ in Fig. 25 can be observed due to the perturbation in the voltage $V_{2}$ at the bidirectional port under heavy load steps. The amplitude and dynamics of this perturbation are determined by the ability of the electronic load connected to the bidirectional port to regulate the voltage under $\mathrm{CV}$ operating mode.

\section{CONCLUSION}

In this paper, an isolated soft-switched TPC to interface with hybrid renewable energy systems is presented. Its operating principle and design considerations are discussed and verified by simulation and experimental results. In order to control the power flow between the different ports, a duty cycle and phase-shift control scheme is adopted. The duty cycle is used to control the power flow between the two independent sources, whereas the phase-shift angle is employed to regulate the output voltage. The state-space modelling and control of the proposed TPC operating in completely demagnetized and fully magnetized mode is presented. The mathematical model is validated by simulation as well as experimental measurements of the plant and line-tooutput transfer functions. The advantage of the proposed topology is that it can be dynamically modelled as individual converters, which makes it possible to design a control strategy with totally uncoupled control variables. This fact makes this topology a very interesting solution in renewable energy applications where an energy storage element is required, since full reutilization of the converter primary side switches is achieved, without having a negative impact in the controllability of the converter. By selecting the renewable source and the energy storage voltages, $V_{1}$ and $V_{2}$, to require a duty cycle approximately to 0.5 the phase-shift value range can be fully utilized. Experimental results demonstrate that the proposed energy/power management solution achieves effective control of the power flow among the input, bidirectional and output ports.

\section{REFERENCES}

[1] F. Blaabjerg, Z. Chen and S. B. Kjaer, "Power Electronics as Efficient Interface in Dispersed Power Generation Systems," IEEE Transactions on Power Electronics, vol. 19, no. 5, pp. 1184 - 1194, 2004.

[2] Z. Chen, J. M. Guerrero and F. Blaabjerg, "A Review of the State of the Art of Power Electronics for Wind Turbines," IEEE Transactions on Power Electronics, vol. 24, no. 8, pp. 1859 - 1875, 2009.

[3] Z. Zhang, R. Pittini, M. A. E. Andersen and O. C. Thomsen, "A Review and Design of Power Electroncis Converters for Fuel Cell Hybrid System Applicaions," Energy Procedia, vol. 20, pp. 301-310, 2012.

[4] W. Zhang, D. Xu, X. Li, R. Xie, H. Li, D. Dong, C. Sun and M. Chen, "Seamless Transfer Control Strategy for Fuel Cell Uninterruptible Power Supply System," IEEE Transactions on Power Electronics, vol. 28, no. 2, pp. 717 - 729, 2013.

[5] A. Tani, M. Camara, B. Dakyo and Y. Azzouz, "DC/DC and DC/AC Converters Control for Hybrid Electric Vehicles Energy ManagementUltracapacitors and Fuel Cell," IEEE Transactions on Industrial Informatics, vol. 9, no. 2, pp. 686 - 696, 2013.

[6] Y. Li, X. Ruan, D. Yang, F. Liu and C. K. Tse, "Synthesis of MultipleInput DC/DC Converters," IEEE Transactions on Power Electronics, vol. 25 , no. 9, pp. $2372-2385,2010$.

[7] H. Tao, A. Kotsopoulos, J. L. Duarte and M. A. Hendrix, "Family of Multiport Bidirectional DC-DC Converters," IET Journals \& Magazines - IEE Proceedings Electric Power Applications, vol. 153, no. 3, pp. 451458, 2006.

[8] H. Wu, J. Zhang and Y. Xing, "A Family of Multiport Buck-Boost Converters Based on DC-Link-Inductors (DLIs)," IEEE Transactions on Power Electronics, vol. 30, no. 2, pp. 735 - 746, 2015.

[9] H. Tao, A. Kotsopoulos, J. L. Duarte and M. A. M. Hendrix, "Transformer Coupled Multiport ZVS Bidirectional DC-DC Converter with Wide Input Range," IEEE Transactions on Power Electronics, vol. 23, no. 2, pp. 771 - 781, 2008.

[10] Y.-M. Chen, Y.-C. Liu and F.-Y. Wu, "Multi-input DC/DC Converter Based on the Multiwinding Transformer for Renewable Energy Applications," IEEE Transactions on Industry Applications, vol. 38, no. 4, pp. 1096 - 1104, 2002.

[11] Z. Zhang, O. C. Thomsen, M. A. E. Andersen and H. R. Nielsen, "Dualinput isolated full-bridge boost $\mathrm{dc}-\mathrm{dc}$ converter based on the distributed transformers," IET Power Electronics, vol. 5, no. 7, pp. 1074 - 1083, 2012. 
[12] H. Krishnaswami and N. Mohan, "Three-Port Series-Resonant DC-DC Converter to Interface Renewable Energy Sources With Bidirectional Load and Energy Storage Ports," IEEE Transactions on Power Electronics, vol. 24, no. 10, pp. 2289 - 2297, 2009.

[13] L. Wang, Z. Wang and H. Li, "Asymmetrical Duty Cycle Control and Decoupled Power Flow Design of a Three-port Bidirectional DC-DC Converter for Fuel Cell Vehicle Application," IEEE Transactions on Power Electronics, vol. 27, no. 2, pp. 891 - 904, 2012.

[14] S. Falcones, R. Ayyanar and X. Mao, "A DC-DC Multiport-ConverterBased Solid-State Transformer Integrating Distributed Generation and Storage," IEEE Transactions on Power Electronics, vol. 28, no. 5, pp. 2192 - 2203, 2013.

[15] H. Matsuo, W. Lin, F. Kurokawa, T. Shigemizu and N. Watanabe, "Characteristics of the Multiple-Input DC-DC Converter," IEEE Transactions on Industrial Electronics, vol. 51, no. 3, pp. 625-631, 2004.

[16] C. Zhao, S. D. Round and J. W. Kolar, "An Isolated Three-Port Bidirectional DC-DC Converter With Decoupled Power Flow Management," IEEE Transactions on Power Electronics, vol. 23, no. 5, pp. $2443-2453,2008$.

[17] Z. Zhang, O. C. Thomsen and M. A. E. Andersen, "Analysis and Design of a Bidirectional Isolated DC-DC Converter for Fuel Cells and Supercapacitors Hybrid System," IEEE Transactions on Power Electronics, vol. 27, no. 2, pp. 848 - 859, 2012.

[18] X. Sun, Y. Shen, Y. Zhu and X. Guo, "Interleaved Boost-Integrated LLC Resonant Converter With Fixed-Frequency PWM Control for Renewable Energy Generation Applications," IEEE Transactions on Power Electronics, vol. 30, no. 8, pp. 4312 - 4326, 2015.

[19] H. Wu, K. Sun, R. Chen, H. Hu and Y. Xing, "Full-Bridge Three-Port Converters With Wide Input Voltage Range for Renewable Power Systems," IEEE Transactions on Power Electronics, vol. 27, no. 9, pp. 3965 - 3974, 2012.

[20] Y. Hu, W. Xiao, W. Cao, B. Ji and J. Morrow, "Three-Port DC-DC Converter for Stand-Alone Photovoltaic Systems," IEEE Transactions on Power Electronics, vol. 30, no. 6, pp. 3068 - 3076, 2015.

[21] H. Al-Atrash, M. Pepper and I. Batarseh, "A Zero-Voltage Switching Three-Port Isolated Full-Bridge Converter," in 28th Annual InternationalTelecommunications Energy Conference, 2006. INTELEC, 2006.

[22] H. Al-Atrash and I. Batarseh, "Boost-Integrated Phase-Shift Full-Bridge Converter for Three-Port Interface," in 2313 - 2321, IEEE Power Electronics Specialists Conference PESC, 2007.

[23] H. Al-Atrash, F. Tian and I. Batarseh, "Tri-Modal Half-Bridge Converter Topology for Three-Port Interface," IEEE Transactions on Power Electronics, vol. 22, no. 1, pp. 341 - 345, 2007.

[24] Z. Qian, O. Abdel-Rahman, H. Al-Atrash and . I. Batarseh, "Modeling and Control of Three-Port DC/DC Converter Interface for Satellite Applications," IEEE Transactions on Power Electronics, vol. 25, no. 3, pp. $637-649,2010$.

[25] W. Li, J. Xiao, Y. Zhao and X. He, "PWM Plus Phase Angle Shift (PPAS) Control Scheme for Combined Multiport DC/DC Converters," IEEE Transactions on Power Electronics, vol. 27, no. 3, pp. 1479 - 1489, 2012.

[26] H. Wu, P. Xu, H. Hu, Z. Zhou and Y. Xing, "Multiport Converters Based on Integration of Full-Bridge and Bidirectional DC-DC Topologies for Renewable Generation Systems," IEEE Transactions on Industrial Electronics, vol. 61, no. 2, pp. 856 - 869, 2014.

[27] H. Wu, J. Zhang, X. Qin, T. Mu and Y. Xing, "Secondary-SideRegulated Soft-Switching Full-Bridge Three-Port Converter Based on Bridgeless Boost Rectifier and Bidirectional Converter For Multiple Energy Interface.," IEEE Transactions on Power Electronics - IEEE Early Access Articles DOI: 10.1109/TPEL.2015.2473002, no. 99, 2016.

[28] Y. Lembeye, V. D. Bang, G. Lefevre and J.-P. Ferrieux, "Novel HalfBridge Inductive DC-DC Isolated Converters for Fuel Cell Applications," IEEE Transactions on Energy Conversion, vol. 24, no. 1, pp. $203-210,2009$.

[29] C. Park, S. Choi and J.-M. Lee, "Quasi-resonant boost-half-bridge converter with reduced turn-off switching loss for $16 \mathrm{~V}$ fuel cell application," in International Power Electronics and Motion Control Conference (IPEMC), 2012.
[30] S. Cuk and R. D. Middlebrook, "A general Unified Approach to modelling switching-power-stages," in PESC, 1976.

[31] D. Maksimovic and S. Cuk, "A unified analysis of PWM converters in discontinuous modes," IEEE Transactions on Power Electronics, vol. 6, no. 3, pp. 476-490, 1991.

[32] L. Risbo, M. Hoyerby and M. A. Andersen, "A versatile discrete-time approach for modeling switch-mode controllers," in IEEE Power Electronics Specialists Conference PESC, 2008.

[33] S. Cuk and R. Middlebrook, "A general unified approach to modelling switching DC-to-DC converters in discontinuous conduction mode," IEEE Power Electronics Specialists Conference, pp. 36 - 57, 1977.

[34] R. D. Middlebrook, "Measurement of loop gain in feedback systems," International Journal of Electronics, vol. 38, no. 4, pp. 485-512, 1975.

[35] L. Technology, "http://www.linear.com/solutions/4673," [Online].

[36] J. Sun, D. Mitchell, M. Greuel, P. Krein and R. M. Bass, "Averaged modeling of PWM converters operating in discontinuous conduction mode," IEEE Transactions on Power Electronics, vol. 16, no. 4, pp. 482492, 2001.

[37] D. Czarkowski and M. K. Kazimierczuk, "Energy-conservation approach to modeling PWM DC-DC converters," IEEE Transactions on Aerospace and Electronic Systems, vol. 29, no. 3, pp. 1059-1063, 1993.

[38] W. Xiao, W. G. Dunford, P. R. Palmer and A. Capel, "Regulation of photovoltaic voltage," IEEE Transactions on Industrial Electronics, vol. 54, no. 3, pp. 1365-1374, 2007.

[39] M. . C. Mira, Z. Zhang, A. Knott and M. A. E. Andersen, "Power Flow Control of a Dual-Input Interleaved Buck/Boost Converter with Galvanic Isolation for Renewable Energy Systems," in IEEE Applied Power Electronics Conference APEC, 2014.

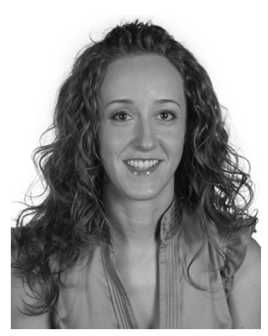

Maria C. Mira (S'13-M'16) received the B.Sc. degree in Telecommunications from Miguel Hernandez University, Elche, Spain, in 2009 and the M.Sc. degree in Electrical Engineering from the Technical University of Denmark, Kongens Lyngby, Denmark, in 2012. She is currently working towards the Ph.D. degree at the Technical University of Denmark.

She was a Visiting Scholar at the Colorado Power Electronics Center (CoPEC), University of Colorado Boulder, Boulder, CO, USA, from April to July 2015. Her main research interests include modelling and control of switchedmode power supplies, bidirectional converters and three-port converters for renewable energy systems.

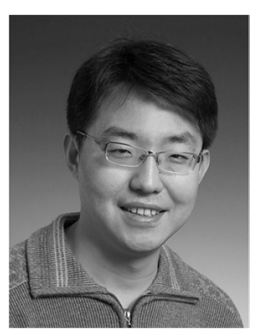

Zhe Zhang (S'07-M'11) received the B.Sc. and M.Sc. degrees in power electronics from Yanshan University, Qinhuangdao, China, in 2002 and 2005, respectively, and the Ph.D. degree from the Technical University of Denmark, Kongens Lyngby, Denmark, in 2010.

$\mathrm{He}$ is currently an Associate Professor with the Department of Electrical Engineering, at the Technical University of Denmark. From 2005 to 2007, he was an Assistant Professor with Yanshan University. From June 2010 to August 2010, he was with the University of California, Irvine, CA, USA, as a visiting scholar. He was a Postdoctoral Researcher and Assistant Professor at the Technical University of Denmark during 2011 and 2014. He has authored or co-authored more than 80 transactions and international conference papers. His current research interests include piezoelectric actuator and 
transformer based power conversion systems; soft-switching power converters; multiple-input dc-dc converters and multilevel dc-ac inverters for renewable energy systems (RES), hybrid electric vehicles (HEV) and uninterruptable power supplies (UPS).

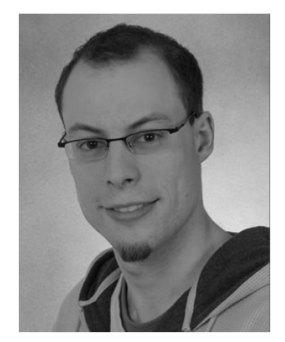

Arnold Knott (M'10) received the Diplom-Ingenieur $(\mathrm{FH})$ degree from the University of Applied Sciences, Deggendorf, Germany, in 2004, and the Ph.D. degree from the Technical University of Denmark, Kongens Lyngby, Denmark, in 2010, working on a research project under the title "Improvement of out-of-band Behaviour in Switch-Mode Amplifiers and Power Supplies by their Modulation Topology."

From 2004 until 2009, he was with Harman/Becker Automotive Systems GmbH in Germany and USA, designing switch-mode audio power amplifiers and power supplies for automotive applications. From 2010 to 2013, he was an
Assistant Professor at the Technical University of Denmark, where he has been an Associate Professor since 2013. His interests include switch-mode audio power amplifiers, power supplies, active and passive components, integrated circuit design, acoustics, radio frequency electronics, electromagnetic compatibility, and communication systems.

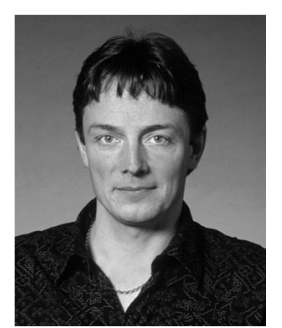

Michael A. E. Andersen (M'88) received the M.Sc.E.E. and Ph.D. degrees in power electronics from the Technical University of Denmark, Kongens Lyngby, Denmark, in 1987 and 1990, respectively.

$\mathrm{He}$ is currently a Professor of power electronics at the Technical University of Denmark, where since 2009, he has been the Deputy Head of the Department of Electrical Engineering. $\mathrm{He}$ is the author or coauthor of more than 200 publications. His research interests include switch-mode power supplies, piezoelectric transformers, power factor correction, and switch-mode audio power amplifiers. 